OUMDESIJ

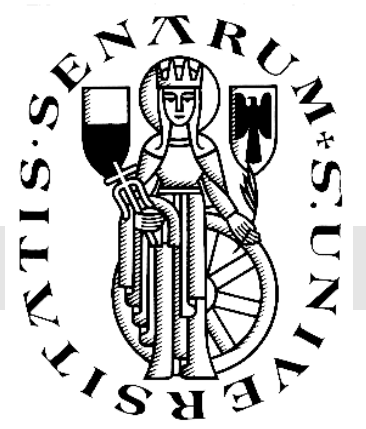

Università degli Studi di Siena

DIPARTIMENTO DI ECONOMIA POLITICA

CARLO ALTAVILLA

LUIGI LUINI

PATRIZIA SBRIGLIA

Information and Learning in Bertrand and Cournot Experimental Duopolies

n. 406 - Ottobre 2003 


\title{
INFORMATION AND LEARNING IN BERTRAND AND COURNOT EXPERIMENTAL DUOPOLIES ${ }^{\S}$
}

\author{
CARLO ALTAVILLA, LUIGI LUINI, PATRIZIA SBRIGLIA \\ Università di Siena - Università di Napoli II \\ altavilla@unina.it-luini@unisi.it_sbriglia@unina.it
}

\begin{abstract}
In this paper we report the results from a series of experiments on Cournot (homogeneous and differentiated products) and Bertrand (differentiated products) duopoly markets with no uncertainty, fixed endpoints and random matching. For each set, the experiments are designed with three alternative information set up: I) no information (participants are only informed on their own payoff for the period), 2) average industrial profit (participants are informed on their own performance, as well as on the average profit in all markets), 3) imitation (players are informed, on request, on their rivals' past successful actions). The effect of different information structures on individual behaviour in market experiments is a long debated issue. Recently, using evolutionary arguments, it has been argued that the imitation of successful strategies induces more competitive equilibria in market games (M. Schaffer, 1989; F. Vega-Redondo 1997). By the same token, the information on the industry's average profitability might induce more collusive outcomes, if such markets signals are perceived by players as aspiration levels and if they therefore try new strategies anytime their profits fall below such threshold (F. Palomino and F. Vega-Redondo, 1999; H. Dixon, 2000). Our aim is to test such predictions in duopoly price and quantity games. We find that the imitation learning rule prevails when players have full information on their rivals' previous choices, and such learning behaviour induces more competitive outcomes in the Cournot market designs. As for the aspiration learning rule, the evidence is unclear. Whilst in the majority of the cases, players experiment new strategies when their payoff falls below the average profit, as predicted by the aspiration rule, we find no evidence of convergence to collusion, though in the Cournot experiments, the fraction of players choosing cooperative actions in the last stages of the game significantly increase in the second information setting.
\end{abstract}

Keywords: Cournot and Bertrand experiments, learning.

J.E.L. classification: C91, D83.

\footnotetext{
$\S$ We are indebted to the University of Siena and the University of Naples II (assegno di ricerca 2003, dr. C. Altavilla) for financial help. Thanks to the University of Zurich for providing the computer software (Z-Tree). We also thank the participants to the COMPLEXITY conference (Aix en Provence, May 2003) for helpful comments. Thanks to Francesco Lomagistro for designing the experiments. The usual disclaimers apply.
} 


\section{Introduction}

In this paper we report the results from a series of experiments on Cournot (homogeneous and differentiated products) and Bertrand (differentiated products) duopoly markets with no uncertainty, fixed endpoints and random matching. For each model, the experiments are designed with three alternative information settings. In the first case, participants are informed only on their own payoff for the period (Experimental Design 1; ED 1, hereafter); In the second case, participants are informed on their own performance, as well as on the average profit in all duopoly markets in the previous period (Experimental Design 2; ED 2, hereafter); Finally, in the third design, players are informed, on request, on their rivals' past actions and payoffs (Experimental Design 3; ED 3, hereafter). In all experimental sessions, however, players were informed on the cost and demand functions and the number of periods the experiments lasted.

The effect of different information settings on firms' behaviour is a long debated issue, and there is little theoretical agreement on their predicted impact on competition ${ }^{1}$. The Nash prediction on oligopoly dynamic models, with fixed endpoints, consider the disclosure of individual firm's decisions or the publication of aggregate statistics on the market performance as irrelevant to the degree of market competition, since individual behaviour should be unaffected in both cases.

An alternative prediction has been put forward in most traditional Industrial Organization models on oligopoly (Stigler, 1964) and has inspired many regulatory and antitrust policies ${ }^{2}$. According to this point of view, whilst the publication of general statistics on the industrial 
profitability has no impact on competition, since behaviour should be unaffected, the full disclosure of individual data is detrimental to competitive practices. In fact, when information is complete, cartels can be enforced, since any defection is immediately detected and punished, and therefore collusion is encouraged.

Recent evolutionary models on learning and bounded rationality take a completely different perspective, and consider all types of information as relevant to individual behaviour, with a final impact on competition, but the predicted effect is substantially different in the two cases we consider (full disclosure of individual data, publication of general statistics on the industrial profitability).

On one side, knowing other people's actions in the past may induce imitation of the more successful strategies (imitate the best). Such behavioural rules will increase the level of competition in the industry (M. Schaffer, 1989; F. Vega-Redondo 1997).

By the same token, the information on the industry's average profitability might induce more collusive outcomes, if such markets signals are perceived by players as aspiration levels and if they therefore try new strategies anytime their profits fall below such threshold (F. Palomino and F. Vega-Redondo, 1999; H. Dixon, 2000).

The aim of our experiments is to provide a test both of the imitation rule and the aspiration rule in duopoly markets, and, more importantly, to test whether the amount and type of information matter and affect the level of competition, as claimed in the evolutionary models.

We find that the imitation learning rule prevails when players have full information on their rivals' previous choices, and such learning behaviour induces more competitive outcomes in all three market models. As for the aspiration learning rule, the evidence is unclear. Whilst in the majority of the cases, players experiment new strategies when their payoff falls below the average profit, as predicted by the aspiration rule, we do not find clear evidence of convergence to collusion, though in two experiments out of 
three, the fraction of players choosing cooperative actions in the last stages of the game significantly increase in the second experimental setting. In all cases, however, we find evidence that the amount and type of information produce changes in behaviour and learning, thus affecting the process of convergence.

There are several experimental papers to which our work is connected (S. Huck, H. T. Normann, J. Oechssler, 1999; S. Huck, H. T. Normann, J. Oechssler, 2000; A. Bosch-Domenech, N. J. Vriend, 2003, H. D. Dixon, P. Sbriglia, E. Somma, 2003, among the others ${ }^{3}$ ).

In particular, the imitation rule has recently received quite a lot of attention (S. Huck, H. T. Normann, J. Oechssler, 2000; A. BoschDomenech, N. J. Vriend, 2003), but the results of these studies are fairly contradictory ${ }^{4}$, since in one case (S. Huck, et al., 2000) the imitation hypothesis is confirmed, while in the other one is rejected. The evidence on the aspiration rule is more scant, though such a learning behaviour has a long historical tradition (H. Simon, 1955, 1956); however, the only experimental study which test the rule in an oligopoly game, show that cooperative outcomes are more likely to occur when players are informed on the average profitability of the industry (H. D. Dixon, P. Sbriglia, E. Somma, 2003), as predicted in the evolutionary models.

\section{Theoretical Background and Experimental Predictions}

The experimental designs were based on three types of duopoly market models. In the first case, firms chose the quantity to produce in each period, goods were homogeneous. The inverse demand function and the corresponding profit function for firm $i$ were, respectively:

$$
\begin{gathered}
p=a-b\left(q_{1}+q_{2}\right) \\
\pi_{i}=(p-c) q_{i}
\end{gathered}
$$

By the same token, in the second case of quantity competition (differentiated goods), market demand and individual profits were represented by the functions: 


$$
\begin{gathered}
p_{i}=a-b\left(q_{i}+\theta q_{j}\right) \\
\pi_{i}=\left(p_{i}-c\right) q_{i}
\end{gathered}
$$

Finally, we consider a model of price competition, where the direct demand function is:

Here, again, profits are:

$$
q_{i}=\alpha-\beta\left(p_{i}-\theta p_{j}\right)
$$

$$
\pi_{i}=\left(p_{i}-c\right) q_{i}
$$

\begin{tabular}{|c|c|c|c|c|c|c|}
\hline & $\mathrm{a}$ & $\mathrm{b}$ & $\theta$ & $\alpha$ & $\beta$ & $\theta$ \\
\hline $\begin{array}{r}\text { COURNOT } \\
\text { H.P. }\end{array}$ & 24 & $\frac{1}{2}$ & & & & \\
\hline $\begin{array}{r}\text { COURNOT } \\
\text { D.P. }\end{array}$ & 24 & $\frac{2}{3}$ & $\frac{1}{2}$ & & & \\
\hline $\begin{array}{r}\text { BERTRAND } \\
\text { D.P. }\end{array}$ & & & & 24 & 2 & $\frac{1}{2}$ \\
\hline
\end{tabular}

Table 1 reports the value of the demand coefficients in the three market models:

TABLE 1: VALUES OF THE DEMAND COEFFICIENTS

Notice that:

$$
\alpha=\frac{a}{b(1+\theta)} \text { and } \beta=\frac{b}{b^{2}\left(1-\theta^{2}\right)} \text {; }
$$

The second duopoly model is therefore an example of product differentiation, where outputs are strategic complements, and, with the corresponding direct demand function, the third model is an example of the same kind, where prices are strategic substitutes. ${ }^{5}$

In all three models, the cost function was given by:

$$
C=c q_{i}
$$

where the marginal cost, $c$, was equal to zero.

Let us concentrate on the symmetric solutions in the market games. We begin with the standard Nash equilibrium in the three cases, by reporting the equilibrium quantities and price in all contexts: 


$$
q_{i}^{C}=\frac{a-c}{3 b}=16 ; \quad q_{i}^{c c}=\frac{a-c}{b(2+\theta)}=14.4 ; \quad p_{i}^{b}=\frac{\alpha-c}{\beta(2-\theta)}=8
$$

where the superscripts stand respectively for the Cournot models (homogeneous, $c$, and differentiated products, $c c$,) and the Bertrand model of competition $(b)$.

The Nash-Cournot and the Nash-Bertrand solutions are a natural benchmark for our tests, and there is wide experimental evidence that such solutions are enforced in the laboratory, under a large number of designs and models' variations ${ }^{6}$. The Nash equilibrium can be implemented in all experimental settings we consider (ED 1, ED 2 and ED 3). The basic requirements for its implementation regard in fact the (finite) number of periods the game lasted and the absence of structural uncertainty (costs, demand and payoffs) and both requirements were met in all sessions. We regard ED 1, however, as a benchmark setting, since no extra information is provided by the organizers. The existence of the "benchmark" setting allows us to state the first experimental prediction:

Claim I: In the duopoly experiments where participants did not receive any extra information on the industrial profitability and the rivals' actions (ED 1), output choices converge to the values reported in (1), and the Nash equilibrium solutions represent the correct prediction for the three market games.

Notice that, as it has been found in a number of recent papers on this specific issue ${ }^{7}$, the emergence of the Nash equilibrium in market games is compatible with several learning rules (best reply, fictitious play, and, in some cases, qualitative response learning), but we do not attempt to analyse individual choices, assuming that the convergence to the Nash equilibrium is determined by some sort of adaptive learning process, without ruling out sophisticated behaviours.

Let us now move to the second aim of our investigation, e.g., the study of the aspiration learning rules. As noticed in the introduction, aspiration rules have a long standing historical tradition in explaining the behaviour of 
imperfectly rational agents. We may recall here $\mathrm{H}$. Simon theory on bounded rationality, but also, the hypothesis of satisfying behaviour in firm's organisational decision making (R Cyert and J. March (1963)). The rationale beyond aspiration rules is that firms, rather than optimising agents, tend to be survivors, and their prior objective is to be at least as profitable as their opponents, because making losses might force their exit from the market (H. Dixon, 2000).

Evolutionary Game Theoretical models (R. Karandikar, D. Mokerjee, D. Ray, 1998; F. Vega-Redondo, 1996; F. Palomino and F. Vega-Redondo, 1999; H. Dixon, 2000) have studied the implication of the aspiration rules in a number of repeated games.

In F. Palomino and F. Vega-Redondo, 1999, a population of agents is randomly paired to play the Prisoner Dilemma game. At each point in time, they can observe the population mean payoff, which is taken to be the individual aspiration level. ${ }^{8}$ Players use a simple decision rule: if they are earning below average they switch $^{9}$, with a positive probability, to a different strategy. It can be proved that, under fairly general conditions, the dynamics of the system converges to a state in which there is a positive fraction of cooperators, the amount of cooperation being dependent on the value of the coefficients in the PD game.

A stronger result is reached by H. Dixon in duopoly Cournot games, where firms adopt a similar rule of behaviour, considering the (overall) average profit as the individual aspiration level.

H. Dixon considers an "economy" composed by several duopoly markets, where firms are matched in each period to play a Cournot game. Firms observe their own payoff, but also the average profit in whole economy (the aspiration level).

At each point in time firms adopt a pure strategy, and, if their payoff is below average, then they are likely to experiment something new. If firms follow aspiration rules, then collusion "will be the "almost" global attractor of the economic system" (H. Dixon, p. 223). 
There is an aspect of the evolutionary models that needs be emphasized. In these models, aspiration are endogenous, since they are driven by the working of the (economic) system; in this respect, the emergence of cooperation might be brought about not directly by the strategic interaction in the individual market (or the individual game), but rather by the market forces (in the Cournot games) ${ }^{10}$, or the general structure and information of the games, in the alternative examples. Going back to our market models, the second theoretical benchmark that will be tested in our experiment is therefore the symmetric joint profit maximising outcome, that might emerge in contexts such the one designed in ED 2. The equilibrium values of the cooperative outcomes in the three market models are reported in (2):

$$
q_{i}^{c}=\frac{a-c}{4 b}=12 ; q_{i}^{c c}=\frac{a-c}{b(2+2 \theta)}=12 ; p^{c c}=\frac{a-c}{2}=12 ; \quad 11
$$

Our second experimental prediction can therefore be stated in the following manner:

Claim II: In the duopoly experiments where participants received information on the industrial profitability, e.g., the average profit in all markets for the previous period (ED 2), output choices converge to the values reported in (2), and the collusive equilibrium solutions represent the correct prediction for the three market games.

Naturally, we also interested in understanding whether information does influence the behaviour of the participants in the experiments, and there is a different pattern of choices between the experimental designs ED 1 and ED 2.

Finally, in the third experimental design, players had free access to the choices of their opponents and imitation was therefore possible.

The impact of imitative behaviour on the equilibrium selection in market games has been analysed in M. Schaffer, 1989 and F. Vega-Redondo 1996, and 1997. According to this line of research, imitation positively influences the degree of competition even in industries with few sellers. When players can observe the opponents' previous choices, Walrasian output levels may 
be reached either as effect of imitation or as effect of spiteful behaviour. In the first case, imitating the best strategies, the firm will increase (decrease) its output every time the market price exceeds (is lower than) the marginal cost (S. Huck, H. T. Normann, J. Oechssler, 2000, p. 41), and this process leads to competitive outcomes. Imitation is regarded to be a reasonable code of behaviour in complex environments, as market games, since it does not require sophisticated reasoning. On the other hand, when there is complete information on previous actions and rewards, spiteful behaviour - the agent chooses actions which might lead to a decrease in his own payoff, but that will produce an even greater loss in his opponent's payoff (beating your opponent) - is also a possible learning rule, and it will lead to Walrasian outcomes in a similar manner.

In order to understand why this is the case, we need to recall some important aspects of the evolutionary models. Firstly, the theoretical framework underlying the concept of Evolutionarily Stable Strategies (ESS) is substantially different in the case of finite populations of agents. In this context, as opposed to the infinite population case, a strategy, in order to be an ESS, needs not to be a Nash equilibrium, i.e., needs not to be a best reply to itself. ${ }^{12}$ The reason why non-Nash equilibria can be stationary points in the evolutionary dynamics lies in the basic fact that what is important for the survival of the strategies/genes (in evolutionary terms) is the magnitude of the payoffs in relative rather than absolute terms. The importance of differential payoffs justifies why a "mutant" strategy might be evolutionary successful, with respect to a "dominant" strategy, even if its gain - for the individual - is lower (in absolute terms) than the gain provided by the other one. What is crucial, in fact, is that the differential payoff of the mutant strategy is higher than that provided by the dominant strategy. Considering the case of spiteful behaviour, for example, this happens every time the individual adopts a specific strategy which yields him a lower payoff relative to other available strategies, but his choice will produce a decrease in the opponent's payoff even greater than his own loss. This ensures that 
the mutant strategy - which is not a best reply to itself - will survive in the long run and defeat the competing strategies/genes.

If we consider a simple market game, where firms choose quantity strategies over a number of periods, it can be proved that the evolutionary stable equilibrium, which is enforceable as a consequence of spite or imitation is the Walrasian equilibrium, e.g., by choosing a Walrasian output, an individual firm may well decrease its own payoff with respect to a, say, a Cournot output, but it will always decrease its rival's payoff even further (see F. Vega-Redondo 1996, 1997). On the other hand, for any Walrasian configuration, no firm will deviate from that output choice, since the deviation would not increase its own profit. In ED 3, we designed an experiment to measure the effects of these codes of behaviour.

In (3) we report the equilibrium values of the Walrasian configurations in the three market models, and, subsequently, we state our final claim.

$$
q_{i}^{c}=\frac{a-c}{2 b}=24 ; \quad q_{i}^{c c}=\frac{(a-c)}{2 b}=24 ; \quad p^{b}=0: 13
$$

Claim III: In the duopoly experiments where participants received complete information on their rivals' choices, (ED 3), output choices converge to the values reported in (3), and the Walrasian equilibrium solutions represent the correct prediction for the three market games.

Table 2 reports the values of prices (quantity) and profits corresponding to the Nash solution and the two alternative theoretical benchmark we have so far considered. 
TABLE 2: EQUILIBRIUM VALUES

\begin{tabular}{|c|c|c|c|c|c|c|c|c|c|}
\hline & \multicolumn{3}{|c|}{ BERTRAND } & \multicolumn{3}{|c|}{$\begin{array}{c}\text { COURNOT } \\
\text { (H.P.) }\end{array}$} & \multicolumn{3}{|c|}{ COURNOT (D.P.) } \\
\hline & $\mathrm{p}$ & q & $\pi$ & $\mathrm{p}$ & $\mathrm{q}$ & $\pi$ & $\mathrm{p}$ & $\mathrm{q}$ & $\pi$ \\
\hline WALRAS & 0 & 24 & 0 & 0 & 24 & 0 & 0 & 24 & 0 \\
\hline NASH & 8 & 16 & 128 & 8 & 16 & 128 & 9.6 & 14.4 & 138.2 \\
\hline JPM & 12 & 12 & 144 & 12 & 12 & 144 & 12 & 12 & 144 \\
\hline
\end{tabular}

\section{Experimental Designs and Financial Incentives}

The experiments were conducted in Siena (May-June 2002) and the subjects were recruited among undergraduate and graduate students of Law, Business and Economics. Participants received a fee for showing up (3 Euro) and they were paid according to their cumulative performance during the experiment (observed profits varied between 8 and 12 Euro per subject). The instructions for the experiment were read aloud at the beginning of each session, but they could also be accessed at any time during the experiment hitting the appropriate key on the computer. There were three trial runs, and any aspect of the structure of the experiment was discussed by the experimenters. Each market game lasted 20 rounds $^{14}$ of one to three minutes each (minimum to maximum time allowed) and time was given for questions or observations, so to minimise any misunderstanding on the working of the computer program. On average, each experiment lasted between 30 and 40 minutes.

The number of participants varied between 16 and 22 (8 to 11 active markets in each period), and the experiments consisted of nine sessions (three for each information design and each market model), 
In the instructions (available on request), participants were informed on the value of the demand parameters and costs. The information about profitability and rivals' actions was described in the instructions for ED 2 and 3, and, during the trial runs, examples were made on how to calculate individual profits, so to clarify the structure of the market games.

Participants could choose quantities (prices) from a finite grid, and, in case of negative profits, which were never observed, it was explained to students that they would use their participation fee in order to pay up their losses.

Our experimental design is closer in spirit to that of S. Huck, et al., 2000, as opposed to the experimental design reported in A. Bosch-Domenech and N. J. Vriend, 2003 - both papers dealing with the imitation hypothesis. It has recently been argued (K. Ostmann, R. Selten, 2001) that the two settings yield different outcomes, with a higher cooperation rate in experiments where subjects had free access to the quantity/profit tables, rather than choosing quantities from finite grids. In our opinion, the reason why cooperation tends to emerge in the former settings is that, viewing the profit table, participants select a smaller set of strategies to play and some choices are never used. This behaviour affects the speed of convergence and the amount of cooperation in the late stages of the game, since players focus their choices on a set of strategies which is closer to the relevant market equilibria and dismiss the other ones right at the outset.

Choosing prices and quantity from a finite grid may slow down the process of convergence, if the individual takes longer to learn which strategies may produce losses, but we believe it lowers the probability of creating framing effects in the experimental design.

\section{Results}

We now report the results from the market experiments, answering the claims that were enunciated in section 2. We will focus on each experimental design, examining first the issue of equilibrium convergence within each information setting (ED 1, ED 2 and ED 3). Comparing the 
data across the three designs for each market model, we will then try to assess whether information did matter and whether it affected the process of equilibrium selection.

- Experimental Design 1: Adaptive learning rules

Figures 1 report the trend of the average quantities in the first experimental setting (ED 1), for each market model, throughout the 20 periods experiments.

\section{INSERT FIGURE 1 HERE}

Observing the time series, it is possible to gain an initial insight on the process of equilibrium convergence in the three models. In all three cases, in fact, the average individual choice converged to values close to the NashCournot equilibrium, but with substantial differences in the Bertrand and Cournot model with differentiated products.

In these two experiments, considering the last three periods of play, one can observe a significant divergence from the equilibrium values of quantity and price, respectively. Average output choices varied in fact between 16.6 and 16.4, exceeding the equilibrium value of 14.4 , whilst, in the Bertrand setting, average prices settled around the equilibrium value of 8 in the periods $13-17$, and then increased in the final stages, reaching the value of 10 in periods $19-20$.

The same conclusion may be reached looking at the relative frequencies of play of the individual strategies (averaged over the last three period), in each model and reported in Figure 2.

\section{INSERT FIGURE 2}

In the first experiment (Fig. 2a), the relative frequencies are distributed on the interval 11-26, with a peak around the Nash value. In the second setting the peak is around the values of $17-18$, which is considerably higher than the Nash equilibrium, and little cooperation is observed in the final stages.

As far as the Bertrand experiment is concerned, there is an opposite situation, with a peak around the Nash value of 8 , and a peak around the values $9-12$, closer to the cooperative equilibrium. 
Is there enough observational evidence to say that the Nash equilibrium is not a good prediction in these market games and claim 1 has to rejected? The answer is no, and we will examine the issue of equilibrium convergence reporting - where possible - the values of the mean square deviation $(\mathrm{MSD})^{15}$ :

$$
\frac{1}{n} \sum_{i}^{n} \frac{\left(x_{i t}-x_{t}^{*}\right)^{2}}{\left(x_{t}^{*}\right)^{2}}
$$

(where $n$ is the number of players in the experiment)

In table 4 we report the values of MSD statistics for the last 5 periods in the three experiments as a measure of convergence to the Nash equilibrium.

TABLE 4: CONVERGENCE TO NASH (MSD)

\begin{tabular}{|c|c|c|c|}
\hline & C.H. & C.D. & B.D. \\
\hline PERIODS & & & \\
\hline 16 & 0.133 & 0.067 & 0.069 \\
\hline 17 & 0.199 & 0.044 & 0.059 \\
\hline 18 & 0.193 & 0.038 & 0.079 \\
\hline 19 & 0.115 & 0.042 & 0.118 \\
\hline 20 & 0.055 & 0.052 & 0.238 \\
\hline
\end{tabular}

The table shows that there is a higher convergence to the Nash equilibrium in the second market model than in the final stages of the Bertrand game and than in the Cournot H.P. model.

Table 5 completes our investigation, comparing the values of the MSD statistics calculated, for period 20, with regard to the three alternative equilibrium configurations (Nash, Collusion and Walrasian equilibrium), in the first experimental design.

TABLE 5: CONVERGENCE TO MARKET EQUILIBRIA (MSD)

\begin{tabular}{|l|l|l|l|}
\hline & \multicolumn{1}{|c|}{ C.H } & \multicolumn{1}{|c|}{ C.D. } & \multicolumn{1}{c|}{ B.D } \\
\hline NASH & 0.055 & 0.052 & 0.238 \\
\hline WALRAS & 0.117 & 0.184 & ---- \\
\hline JPM & 0.247 & 0.110 & 0.103 \\
\hline
\end{tabular}


In two cases out of three (with the exception of the Bertrand market), the Nash prediction provides a lower values of the MSD. It must be noticed that, since the values of the statistics range between 0 and 1 , there is a significant difference in both Cournot markets, the Nash equilibrium being the best prediction for the games. As for the Bertrand experiment, if we consider the value of the long run profits ${ }^{16}$, that is equal to 122,7 , and the fact that the profits had a low growth rate throughout the experiment (1.09), it can be sustained that also in this case the Nash prediction is the most successful explanation for the individual behaviour.

What we have examined so far allows us to provide an answer to Claim 1:

Result 1: When players are not informed on their rivals' actions nor on the average profitability, the Nash prediction results to be a robust prediction of the individuals' behaviour in two cases out of three. In the Bertrand market, play converge to the Nash value during the experiment and then diverge in the final stages.

\section{- Experimental Design 2: Aspiration learning}

We will proceed now to study the second set of data, corresponding to ED 2. As before, in Figure 3 and 4 we report, respectively, the output (price) trends and the relative frequencies of play, averaged over the last three periods in each session.

\section{INSERT FIGURE 3 AND 4}

Two things can immediately be noticed from Figure 3. First, there is no indication that choices were converging towards the collusive equilibrium (in two cases, Cournot D.P. and Bertrand D.P. there was on the contrary a closer convergence to Nash - e.g., a decrease (increase) in competitiveness in the Cournot (Bertrand) model in the final stages of the games). Second, the time series show a higher speed of convergence if compared to the first experimental design (ED 1). In the market model Cournot H.P. the average quantity (in the last three periods) was around the value of 17.8, and it was not significantly different from the value of the average output in the same 
model in ED 1; in the second market model (Cournot D.P.), however, the average quantity was significantly lower than in the alternative information setting (ranging in ED 2 around the values of 14-15). By the same token, in the Bertrand model, prices approached the Nash value of 8 (the average price varied around 7.6 and 8.3), while in ED 1 they ranged around the average value of 10 .

If we look at the relative frequencies of strategies' play, averaged over the last three periods (Figure 4), there is a slightly different picture which can be gained from this set of data. In fact, in two cases out of three (both in the Cournot models), we can actually see a significant increase - compared to the same model in the ED 1 design - in the proportion of subjects who were playing the strategies 11-12 (close to the Collusion value). In the Cournot model with homogeneous products, the cumulative frequency of participants playing strategies 11-12 increased from 1.8 per cent (ED 1) to almost 11 per cent (ED 2). In the second Cournot model, there was an increase in cooperation from 1.38 p.c. to about 16.7 p.c..

The increase in cooperation is however not sufficient to determine a convergence to the joint profit maximising outcome. As before, we analyse the process of convergence in Tables 6 and 7 .

TABLE 6: CONVERGENCE TO COLLUSION (ED 2)

\begin{tabular}{|c|c|c|c|}
\hline & C.H. & C.D. & B.D. \\
\hline PERIODS & & & \\
\hline 16 & 0.426 & 0.297 & 0.199 \\
\hline 17 & 0.511 & 0.296 & 0.186 \\
\hline 18 & 0.464 & 0.470 & 0.200 \\
\hline 19 & 0.408 & 0.270 & 0.144 \\
\hline 20 & 0.488 & 0.281 & 0.146 \\
\hline
\end{tabular}

TABLE 7: CONVERGENCE TO NASH (ED 2)

\begin{tabular}{|c|c|c|c|}
\hline & C.H. & C.D. & B.D. \\
\hline PERIODS & & & \\
\hline 19 & 0.108 & 0.100 & 0.192 \\
\hline 20 & 0.151 & 0.113 & 0.125 \\
\hline
\end{tabular}


The comparison between the measures of convergence to the Nash equilibrium and to the Collusive equilibrium confirms what we have so far stressed, that is, information on the average industrial profitability does have an effect on cooperation, but there is no evidence of convergence to the JPM outcome. This can be stated as follows:

Result 2: When players are informed on the average industrial profitability, the Nash prediction still results to be a robust prediction of the individuals' behaviour in all three market models. However, in both the Cournot markets, there was a significant increase in the proportion of subjects playing strategies close to the JPM outcome.

\section{- Experimental Design 3: Imitation or Spite}

We finally explore the effects of imitation or spite in market models, by looking at the evidence in the third experimental design (ED 3)

\section{INSERT FIGURES 5 AND 6}

In both Figure 5 and 6, we report the average quantities (prices) and relative frequencies of play, averaged over the last three periods. The difference of results between this experimental design and the other two is immediately evident. In both the Cournot models, the average quantities ranged between 20-24, e.g., closer to the Walrasian theoretical benchmark. In the Bertrand setting the average prices ranged around 5-7.

Table 6 clarifies some aspects of the experiments. In the first Cournot model, average quantities were around 20-22, close to the Walrasian equilibrium output, and the relative frequencies show that, in the last three periods, the Walrasian choice (23-24) was the most used strategy among players. In the two remaining cases, there was a slower convergence to the Walrasian values, but the average quantity (20-21) and price (6-7) were significantly higher (lower) to the quantity and price achieved in the alternative information contexts. Notice also that players chose actions closer to the Walrasian levels than to the Nash equilibrium. Table 8 and 9 complete our analysis, examining the values of the MSD scores in the 
Cournot settings, which appear to confirm the conclusions drawn from Figures 5 and 6 . As before, we measure the process of convergence to the predicted outcome stated in Claim 3 and to the alternative equilibrium benchmark represented by the Nash equilibrium

TABLE 8: CONVERGENCE TO WALRASIAN OUTCOMES (ED 3)

\begin{tabular}{|c|c|c|c|}
\hline & C.S. & C.D. ${ }^{*}$ & B.D. \\
\hline PERIODS & & & \\
\hline 16 & 0.016 & 0.061 & ---- \\
\hline 17 & 0.025 & 0.059 & --- \\
\hline 18 & 0.047 & 0.042 & ---- \\
\hline 19 & 0.027 & 0.045 & ---- \\
\hline 20 & 0.041 & 0.049 & --- \\
\hline
\end{tabular}

* Periods 11-15

TABLE 9: CONVERGENCE TO NASH (ED 3)

\begin{tabular}{|c|c|c|c|}
\hline & C.H. & C.D. & B.D. \\
\hline PERIODS & & & \\
\hline 19 & 0.137 & 0.132 & 0.091 \\
\hline 20 & 0.153 & 0.122 & 0.096 \\
\hline
\end{tabular}

The comparison among the different market models shows a marked difference between the Cournot duopolies and the Bertrand market. The long run profit value in the latter case was in fact equal to 111,6 , lower than the profit value estimated on the benchmark data (122.7), but significantly higher than the theoretical predicted value in the Walrasian setting. It must be added, however, that in the present setting the growth rate of profits in the Bertrand market was indeed negative (-0.98).

Examining the tables and the values of the long run profit, we can conclude that in the two Cournot settings the imitation hypothesis work, and both markets are more competitive than in the previous experimental design. As for the Bertrand model, we do not find a significant difference in 
final equilibrium values in ED 2 and ED 3, if not that in this third setting, prices tend to be lower than in both the alternative contexts.

We are able now to state our third result and therefore to provide an answer to Claim 3:

Result 3: When players are informed on their rivals' past actions and success, the Walrasian equilibrium values result to be a robust prediction of the individuals' behaviour in both the Cournot markets, which are significantly more competitive than in the alternative designs. In the Bertrand model were lower than in the previous settings, but the long run value of the average profit was still close to Nash prediction.

There is a final aspect of our investigation that we wish to underline, and it is related to the general impact of information on behaviour. Does information matter? How information affected the behaviour of the experimental subjects? We can answer to both questions by looking at the time series presented in this section. Information does affect individual behaviour: we performed a $\chi^{2}$ test to compare the ED 2 and ED 1 and ED 3 and ED1, respectively, and we rejected the null hypothesis that there was no difference among the series (5\% significance level). The question on how information affects behaviour is an interesting one and has two answers. First in Ed 2 and ED 3, there was a faster process of convergence to a market equilibrium (information affects the speed of convergence). Second, information lowered the variance of the individuals' choices. This implies that subjects used all types of information we provided to build up their decisional routines. We feel that this is a good result in support of the evolutionary models.

\section{Changing regimes: the study of aspiration learning}

The results of the previous section indicate that aspiration rules fail the convergence test, e.g., we do not observe convergence to the Collusive 
equilibrium outcome in the three duopoly markets under investigation. This result poses the question as to whether aspiration rules are plausible codes of behaviour in complex environments, as market games, and how common they became among the subjects engaged in the ED 2 experiments.

We addressed both questions by estimating Markov-switching autoregressive models (henceforth $M S-A R$ ) on the individual data set of the 50 subjects participating in the three sessions in Ed 2. We recall here that the rationale beyond aspiration rules is that the probability that individuals change their choice increases with the profit differential between their payoff and the observed previous period average payoff. In the following, we assume that the dynamic of the discrete shifts follows a two state Markov process with an $A R(1)$ component for each player.

Formally, the decision rule may be expressed as a $M S M(2)-A R(1)$ model $^{17}$ of the form:

$$
y_{t}-\mu_{s(t)}=\alpha\left\lfloor y_{t}-\mu_{s(t-1)}\right\rfloor+\varepsilon_{t} \quad, \quad \varepsilon_{t} \approx N\left(0, \sigma^{2}\right)
$$

where $y_{t}$ represents the difference between the individual profit and the average market profit; and the unobserved random variable $s(t)$, is a generic ergodic Markov chain defined by the transition probabilities:

$$
p_{i j}=P(s(t)=j \mid s(t-1)=i) \text { and } \sum p_{i j}=1 ; \forall i, j \in(1,2)
$$

Specifically, $s(t)$ takes the values of 1 if a player is in a low profit state (which means the subject tries new strategies- experimentation state) and 2 if a player is in a high profit regime (the subjects does not try new strategies- no experimentation state); the conditional mean, $\mu_{s(t)}$, switches between the two states:

$$
\mu_{s(t)}=\left\{\begin{array}{lll}
\mu_{s(t)}<0 & \text { if } \mathrm{s}_{\mathrm{t}}=1 \quad \text { ( noexperimention) } \\
\mu_{s(t)}>0 & \text { if } \mathrm{s}_{\mathrm{t}}=2 \text { ( experimention) }
\end{array}\right.
$$


The transition probabilities provide the probability of moving from one state to another. Our hypothesis is that the above process follows a 2-state Markov chain. It is then possible to collect the transition probabilities in a $2 \times 2$ transition matrix:

$$
P=\left[\begin{array}{ll}
p_{11} & p_{12} \\
p_{21} & p_{22}
\end{array}\right]
$$

where $p_{i j}$ represents the probability of moving from state $i$ to state $j$. In other words, $p_{12}$ is just the fraction of the times that the system is in state 1 and moves to state 2 .

Maximum Likelihood Estimates (MLE) provide the estimates of the models' coefficients and of the unobserved Markov chain, testing the existence of the two regimes in the individuals' decision process.

In Tables 10, 11 and 12 (see Appendix) the whole MLE estimates are reported for the two Cournot experiments and the Bertrand market, respectively. The signs of the estimated coefficients for the conditional mean in the first state are for each player negative, representing therefore the experimentation state.

The estimated transition probabilities in column 4 and column 5 of table 10,11 and 12, representing the probability of moving from one state to another are, for almost all players, very low. This means that the two regimes are estimated to be very persistent.

Figures 7,8 and 9 complete our investigation reporting the individual smoothing probability of regime 1 together with the observed values of $y_{t}$. The Figures report the estimated probabilities for each player in different contexts. In particular, the figures do not report the smoothed probabilities for player 15 in Bertrand, player 16 in Cournot DP and players 13, 14 and 17 in Cournot HP. For those players the Wald test does not support the existence of two states operating during the experiments. 
The overall picture which can be gained by our hypothesis testing is that ${ }^{18}$ the aspiration rule is adopted in the large majority of the cases. From the Figures is possible to observe that the probability of being in the experimentation state is relatively high each time the difference between the individual profit and the average market profit is lower than zero.

The significance of the parameters estimated by maximum likelihood is tested by applying standard Wald test.

In particular, a further step of the analysis consists of testing whether there have been two regimes operating over the sample period. Implementing the following Wald test can assess this hypothesis:

$$
\begin{aligned}
& H_{0}=p_{11}=1-p_{22} \\
& \frac{\left[p_{21}-\left(1-p_{12}\right)\right]^{2}}{\operatorname{var}\left(p_{21}\right)+\operatorname{var}\left(p_{21}\right)+2 \operatorname{cov}\left(p_{21} p_{21}\right)}
\end{aligned}
$$

where the above statistic is distributed as a $\chi^{2}(1)$.

The results of Wald tests are reported in the last column of Table 10-1112. In particular, for each player the table report whether the test cannot reject the existence of the two states (YES in Tables) at 95\% confidence level or, on the contrary, the test reject the null hypothesis (NO in Tables).

As we can see from Table $10-11-12$ the Wald tests easily reject the hypothesis of having only one state operating during the sample period for a large number of players. In particular, in the Bertrand experiment, for 7 player out of 16 the test reject the presence of two regimes while for the Cournot DP and Cournot HP models the number of tests that reject the null hypothesis is respectively 6 and 3 . These results corroborate the evidence coming from the previous section: the players operating in the Cournot models are more competitive with respect to the player in the Bertrand model. 
From what we have said so far, the aspiration rule can be seen as a successful prediction for individuals' behaviour, although there is no sufficient evidence that aspiration leads to Pareto outcomes in oligopoly games.

\section{Conclusion}

In this paper we have tried to assess the importance of information on learning behaviour in several experimental markets. We have considered three informational settings and we have studied the equilibrium convergence process in three market models, for each of the alternative scenarios. Our investigation has provided some relevant insights in the problem. First, information does matter: the process of equilibrium convergence is, in fact, quite different in the alternative contexts. Second, information strongly affect the selection of the final equilibrium, as shown by the experimental evidence. Third, information affects the process of individual learning, as it is proved by our analysis of the aspiration rule. These three conclusions are, in our opinion, a positive, though not conclusive, test for the recent evolutionary theory on individual learning and bounded rationality. Our work leaves, in fact, two unresolved puzzles. First, though pervasive, aspiration rules do not lead to collusion. Moreover, we do not attempt a comparison among the different rules, nor it is possible to test which information (e.g., individual firms' data or information on the average industrial profitability) would be more relevant for the individual choice process. We believe that both problems should attract attention in the future, in order to provide complete tests of the alternative rationality paradigms. 


\section{References}

Bosh-Domènech, A., N. J. Vriend; (2003) Imitation of Successful Behavior in Cournot Markets, Economic Journal, 113, April, 495-524

Camerer, C., H. Teck-Hua; (1999) Experience-Weighted Attraction Learning in Normal Form Games; Econometrica, 67, 4, 827-74

Cyert R.M., J.G. March (1963), A Behavioral Theory of the Firm, Englewood Cliffs, NJ, Prentice Hall;

Dixon, H. D., 2000, Keeping Up with the Joneses: Competition and the Evolution of Collusion; Journal of Economic Behavior and Organization, 43, 2, 223-38;

Dixon H.D., P. Sbriglia, E. Somma (2003) Learning to collude: an experiment on learning and equilibrium selection in oligopoly; mimeo, University of Naples II;

Erev, I., A.E. Roth; (1998) Predicting How People Play Games: Reinforcement Learning in Experimental Games with Unique, Mixed Strategy Equilibria; American Economic Review, 88, 4, 848-81;

Fouraker L.E., S. Siegel, (1963) Bargaining Behavior, NY, McGrawHill;

Hamilton J.D. (1994) Time Series Analysis, Princeton, Princeton University Press;

Hamilton J.D., B. Raj (2002), New Directions in Business Cycle Research and Financial Analysis, Empirical Economics, 27, 2, 149-62;

Holt C.A. (1995) Industrial Organization: a Survey of Laboratory Research, in: J. Kagel, A. Roth (eds), The Handbook of Experimental Economics, Princeton UP, Princeton, NJ; 349-434;

Huck, S., H.T. Normann, J. Oechssler (1999). Learning in Cournot Oligopoly--An Experiment; Economic Journ,al, 109, C80-95;

Huck, S., H.T. Normann, J. Oechssler, (2000) Does Information about Competitors' Actions Increase or Decrease Competition in Experimental Oligopoly Markets?, International Journal of Industrial Organization, 2000, 18, 1, 39-57; 
Karandikar, R., D. Mokherjie, D. Ray, F. Vega Redondo (1998), Evolving Aspiration and Cooperation, Journal of Economic Theory, 80, 292-331;

Lupi P., P. Sbriglia (2003) Exploring Human Behaviour and Learning in Experimental Cournot Settings, Rivista Internazionale di Scienze Sociali, n.3.

Martin S. (2002), Advanced Industrial Economics, 2d ed., Oxford, Blackwell;

Nagel, R., N.J. Vriend; (1999) An Experimental Study of Adaptive Behavior in an Oligopolistic Market Game; Journal of Evolutionary Economics, January, 9, 1, 27-65;

Ostmann, A., R. Selten (2001), Imitation Equilibrium, Homo oeconomicus, 119-149;

Palomino, F., F. Vega-Redondo, (1999), Convergence of Aspirations and (Partial) Cooperation in the Prisoner's Dilemma; International Journal of Game Theory, 28, 4, 465-88;

Rassenti, S.,, S. Reynolds, V.L. Smith, F. Szidarowsky (2000), Adaptation and Convergence of Behavor in Repeated Experimental Cournot Games, Journal of Economic Behavior and Organization, 41, 2, 117-46;

Simon, H.A. (1955) A Behavioral Model of Rational Choice, Quarterly Journal of Economics, 69, 1, 129-38;

Simon, H.A. (1956) A Comparison of Game Theory and Learning Theory; Psychometrika, 21, 267-72;

Schaffer M. (1989), Are Profit Maximazers the Best Survivors? A Darwinian Model of Economic Natural Selection; Journal of Economic Behavior and Organization, 12, 29-45;

Stigler G.J. (1964) A Theory of Oligopoly, Journal of Political Economy, 72, 1, 44-61;

Vega-Redondo, F., (1996) Evolutionary Games and Economic Behavior, Oxford, Oxford U.P.;

Vega-Redondo, F. (1997), The Evolution of Walrasian Behavior; Econometrica, 1997, 65, 2, 375-84;

Vives, X., (1985), Efficiency of Bertrand. and Cournot Equilibria with Product Differentiation, Journal of Economic Theory, 36, 166-175. 


\section{Endnotes}

${ }^{1}$ S. Huck, H.-T. Normann, J. Oechssler, 2000.

${ }^{2}$ See S. Huck, H.-T. Normann, J. Oechssler, 2000, for a survey of European and American anti-trust policies on the publication of individual firms' data.

${ }^{3}$ The study of learning and behaviour in oligopoly has a long standing tradition in the experimental field of research. On the specific issue of information and behaviour, we recall here the seminal work of C. Fouraker and S. Siegel (1963); for a more general survey on experimental oligopoly, see C. A. Holt (1995).

${ }^{4}$ It must be said that the divergences between the results of two papers can be partly explained by the different experimental settings and models. The two experiments, in fact, differ in the number of firms in the market (two rather than four) and the design (in S. Huck et al., 2000 players chose actions from a finite grid; in A. Bosch-Domenech and N. Vriend, players could view the quantity/profit table before making their own choice).

${ }^{5}$ X. Vives (1985) showed that Bertrand settings are more competitive than Cournot settings, and this result is confirmed in experimental analyses on oligopoly markets ( $\mathrm{S}$. Huck, et al., 2000). We examine this point in a duopoly context, that is proved to be less competitive than 4-firms market, as in S. Huck et al., 2000.

${ }^{6}$ C. Holt, 1995.

${ }^{7}$ S. Rassenti, S. S. Reynolds, V. L. Smith. and F. Szidarovszky, 2000; R. Nagel and N. Vriend, 1999; S. Huck, H. Normann and J. Oechssler, 1999, P. Lupi, P. Sbriglia, 2003.

8 Aspiration might however be linked to alternative statistics of the payoff distribution, such as the mode or the median; the authors prove that, also in these alternative settings, the model converges to a similar long run equilibrium.

${ }^{9}$ The "switching rate" is positively related to the magnitude of the profit differential.

${ }^{10}$ For this reason, H. Dixon defines his model a model of "social" learning.

11 The equilibrium values of output and prices are the same in the Bertrand and the Cournot settings (S. Martin, 2002).

${ }^{12}$ See F. Vega-Redondo, 1996, chapter 2; M. Schaffer, 1989.

${ }^{13}$ For the equilibrium values in the differentiated products models we follow S. Huck, et al., 2000. The values are calculated maximising the profit differential between firm $i$ choosing strategy $q_{i}$ and firm $j$ choosing strategy $q_{j}^{\prime}$, that is: 


$$
\Delta\left(q_{i}, q_{j}^{\prime}\right)=\pi\left(q_{i}, q_{j}^{\prime}\right)-\pi\left(q_{j}^{\prime}, q_{i}\right) .
$$

${ }^{14}$ In one case (Cournot D.P., ED 3) the experiment lasted 15 rounds, due to software failures. We include this data because, as our tests show, there was convergence to a market equilibrium even within this shorter session.

${ }^{15}$ There are several measure of the previsional success of learning theories. The MSD statistics has been used in several experimental paper (see for reference: I. Erev and A. Roth, I., 1998; C. Camerer and Teck-Hua Ho, 1999).

${ }^{16}$ The long run profit values are computed by estimating an asymptotic unit root model. The model consists of the estimation of equations of the form:

$\operatorname{Ln} X_{t}=\alpha+\beta \operatorname{Ln} X_{t-1}+\mathcal{\varepsilon} ; \quad$ where $\mathrm{X}_{\mathrm{t}}$ is the average profit in period $t$ ( $t=$ $1,2, \ldots 20)$. It is easy to check that:

$$
\operatorname{Lim}_{t \rightarrow \infty} X_{t}=\exp \left(\frac{\alpha}{1-\beta}\right) \text {. }
$$

${ }^{17}$ These models, studied by Hamilton J. (1990), have been extensively used for their ability in replicating business cycle features. In particular, as in MS-AR models the regime shift governing process generates dynamic factor structures, they synthesize both non-linear and dynamic factors modelling for evaluating the macroeconomic fluctuations. The non-linearity of the MSM arises because the process is subject to discrete shift in the mean, between the two states. 


\section{Appendix}

Table 10: Maximum Like lihood Estimates of Parameters

(Bertrand)

\begin{tabular}{lcccccc} 
& $\mu_{1}$ & $\mu_{2}$ & $\alpha_{1}$ & $\mathrm{p}_{12}$ & $\mathrm{p}_{21}$ & Test \\
\hline \hline Player 1 & -76.25 & 2.97 & -0.20 & 0.00 & 0.45 & Yes \\
Player 2 & -5.84 & 29.30 & -0.01 & 0.26 & 0.08 & Yes \\
Player 3 & -30.14 & 25.86 & -0.28 & 0.09 & 0.01 & Yes \\
Player 4 & -0.24 & 57.90 & -0.26 & 0.59 & 0.15 & Yes \\
Player 5 & -119.34 & 6.79 & 0.12 & 0.01 & 0.25 & Yes \\
Player 6 & \multicolumn{5}{c}{ NOT ERGODIC } \\
Player 7 & -2.31 & 108.91 & 0.13 & 0.72 & 0.08 & No \\
Player 8 & -5.56 & 1.44 & 0.35 & 0.35 & 0.28 & No \\
Player 9 & -89.11 & -5.14 & -0.33 & 0.35 & 0.09 & Yes \\
Player 10 & 17.94 & 100.12 & 0.08 & 0.50 & 0.01 & No \\
Player 11 & -112.25 & 19.40 & -0.03 & 0.04 & 0.33 & Yes \\
Player 12 & -57.16 & 7.25 & -0.48 & 0.08 & 0.49 & Yes \\
Player 13 & -16.84 & 71.09 & -0.32 & 0.24 & 0.02 & Yes \\
Player 14 & -11.83 & -11.30 & 0.25 & 0.33 & 0.28 & No \\
Player 15 & 4.40 & 4.68 & -0.42 & 0.32 & 0.33 & No \\
Player 16 & 1.33 & 69.30 & -0.66 & 0.82 & 0.26 & Yes
\end{tabular}

Table 11: Maximum Likelihood Estimates of Parameters (Cournot DP)

\begin{tabular}{lcccccc} 
& $\mu_{1}$ & $\mu_{2}$ & $\alpha_{1}$ & $\mathrm{p}_{12}$ & $\mathrm{p}_{21}$ & Test \\
\hline \hline Player 1 & 11.69 & 14.01 & -0.35 & 0.57 & 0.31 & No \\
Player 2 & -102.46 & 1.70 & -0.05 & 0.12 & 0.80 & Yes \\
Player 3 & -10.40 & 17.18 & -0.12 & 0.50 & 0.24 & No \\
Player 4 & -1.18 & 19.15 & -0.20 & 0.04 & 0.64 & No \\
Player 5 & -63.76 & 4.29 & -0.84 & 0.32 & 0.66 & Yes \\
Player 6 & -11.41 & 38.88 & -0.41 & 0.20 & 0.08 & Yes \\
Player 7 & -1.68 & 44.78 & -0.34 & 0.89 & 0.11 & Yes \\
Player 8 & -15.46 & 20.66 & -0.48 & 0.60 & 0.26 & Yes \\
Player 9 & -96.72 & 11.52 & -0.23 & 0.00 & 0.17 & Yes \\
Player 10 & -3.86 & 4.39 & -0.32 & 0.27 & 0.32 & No \\
Player 11 & -85.23 & 3.15 & -0.18 & 0.02 & 0.50 & Yes \\
Player 12 & -25.73 & 8.45 & -0.43 & 0.06 & 0.25 & Yes \\
Player 13 & -82.55 & 4.02 & -0.01 & 0.22 & 0.62 & Yes \\
Player 14 & -4.82 & 54.95 & -0.15 & 0.56 & 0.03 & Yes \\
Player 15 & -1.36 & 4.05 & -0.02 & 0.31 & 0.27 & No \\
Player 16 & -13.45 & 13.37 & -0.48 & 0.32 & 0.38 & No
\end{tabular}


Table 12: Maximum Likelihood Es timates of Parameters

(Cournot HP)

\begin{tabular}{lcccccc} 
& $\mu_{1}$ & $\mu_{2}$ & $\alpha_{1}$ & $\mathrm{p}_{12}$ & $\mathrm{p}_{21}$ & Test \\
\hline \hline Player 1 & -15.93 & 38.35 & -0.38 & 0.26 & 0.31 & Yes \\
Player 2 & -17.09 & 8.41 & 0.32 & 0.23 & 0.26 & No \\
Player 3 & -51.63 & 41.83 & -0.56 & 0.45 & 0.48 & Yes \\
Player 4 & -36.66 & 40.78 & -0.51 & 0.64 & 0.31 & Yes \\
Player 5 & -16.04 & 72.78 & 0.21 & 0.65 & 0.35 & Yes \\
Player 6 & -5.09 & 4.99 & -0.63 & 0.42 & 0.35 & No \\
Player 7 & -53.05 & 15.33 & -0.64 & 0.13 & 0.75 & Yes \\
Player 8 & -14.86 & 10.99 & -0.28 & 0.14 & 0.02 & Yes \\
Player 9 & -9.29 & 79.06 & -0.17 & 0.56 & 0.09 & Yes \\
Player 10 & -20.20 & 16.45 & -0.49 & 0.18 & 0.35 & Yes \\
Player 11 & -7.81 & 58.26 & -0.61 & 0.24 & 0.25 & Yes \\
Player 12 & -30.40 & 8.60 & -0.49 & 0.14 & 0.42 & Yes \\
Player 13 & -8.75 & 14.43 & -0.04 & 0.31 & 0.48 & Yes \\
Player 14 & -22.58 & 22.24 & -0.31 & 0.35 & 0.32 & Yes \\
Player 15 & -15.45 & 56.33 & -0.29 & 0.94 & 0.06 & Yes \\
Player 16 & -34.73 & 42.40 & 0.15 & 0.68 & 0.32 & Yes \\
Player 17 & -4.22 & 4.28 & -0.03 & 0.23 & 0.34 & No \\
Player 18 & -27.14 & 55.18 & 0.13 & 0.38 & 0.28 & Yes
\end{tabular}


Figure 7: Smoothed Probabilities of Regime 1 (Bertrand)

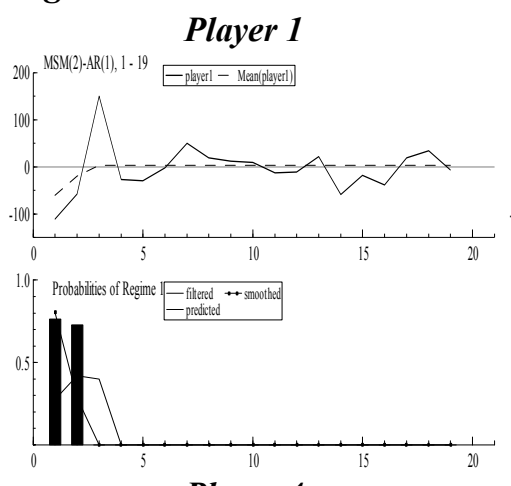

Player 4

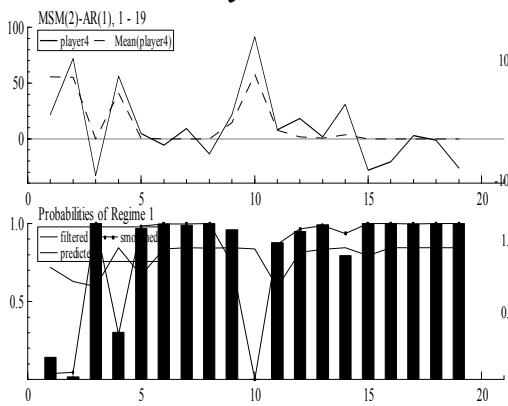

Player 7

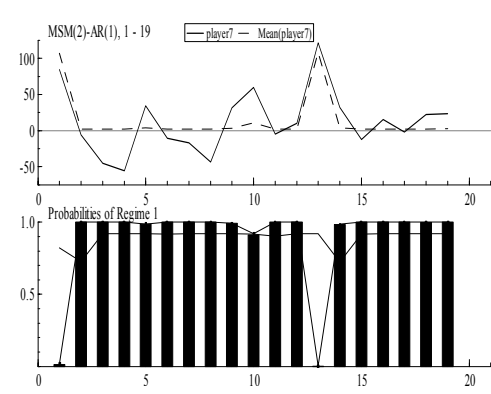

Player 10

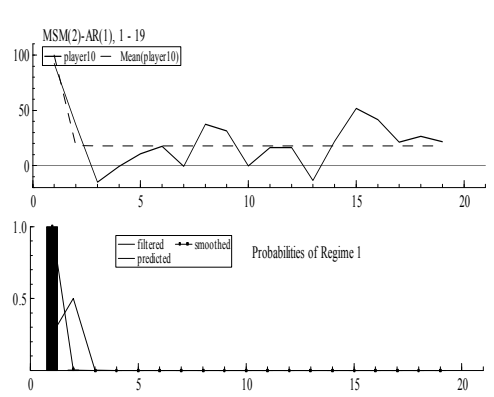

Player 13

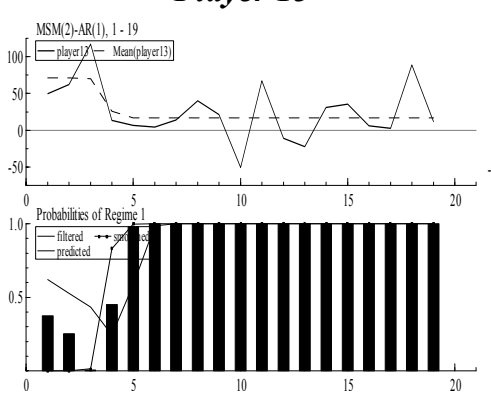

Player 2

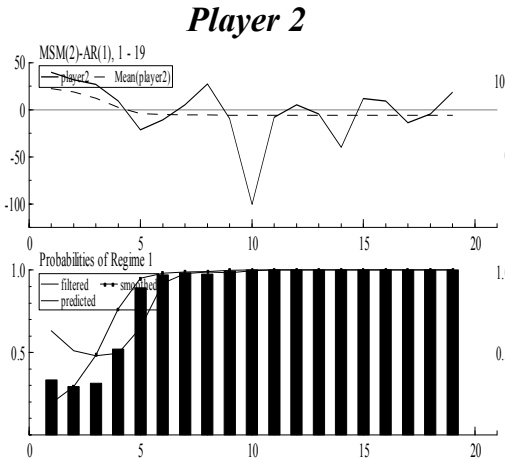

Player 5
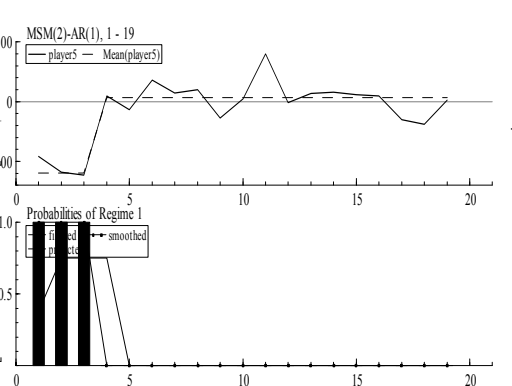

Player 8

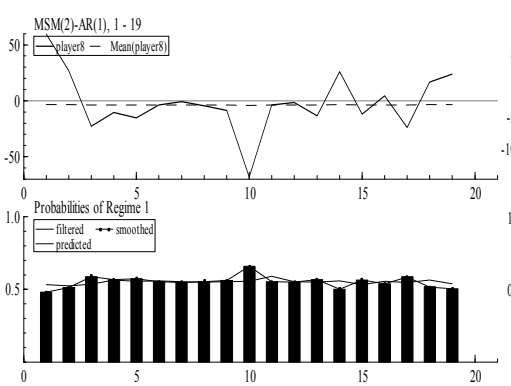

Player 11
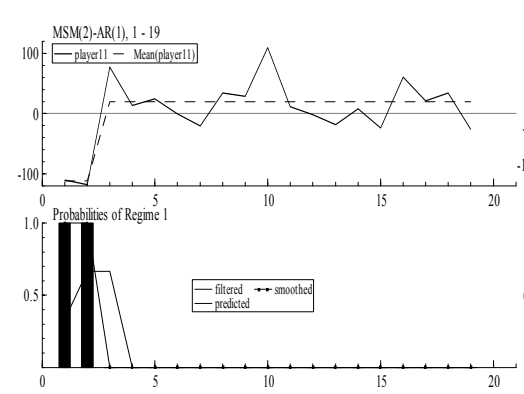

Player 14

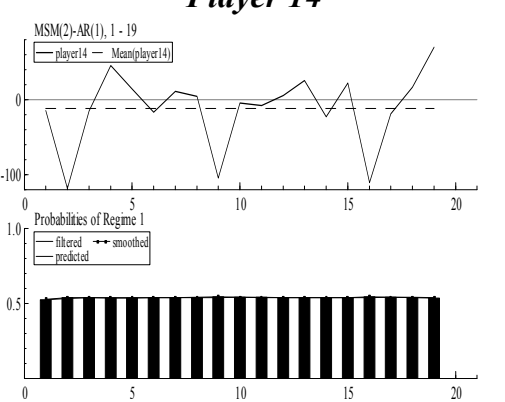

Player 3

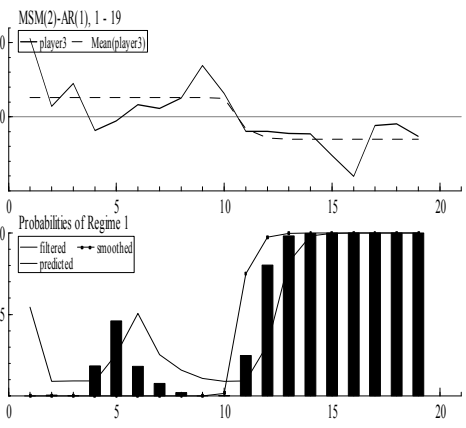

Player 6

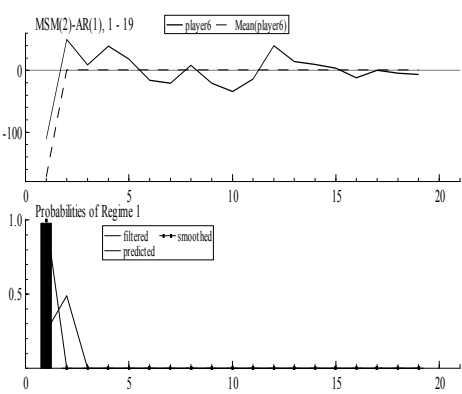

Player 9

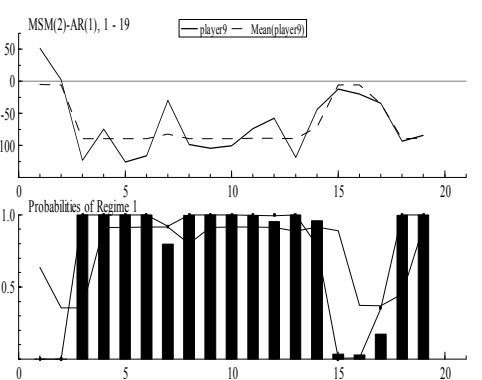

Player 12

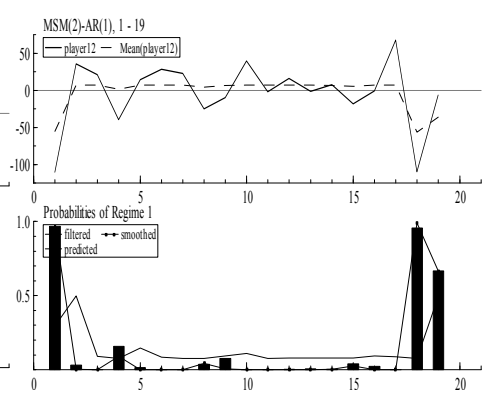

Player 16

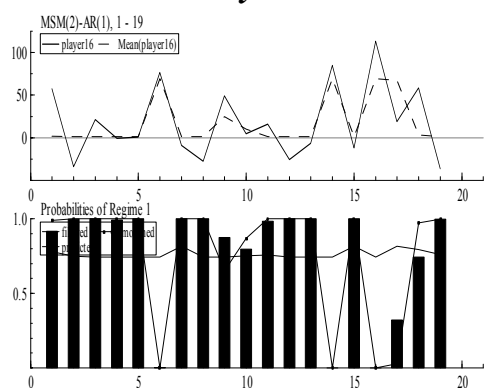


Figure 8: Smoothed Probabilities of Regime 1 (Cournot DP)

Player 1

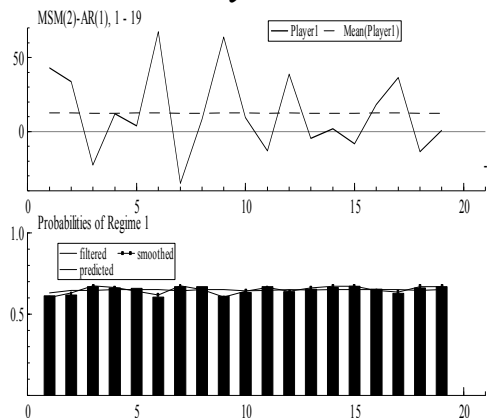

Player 4

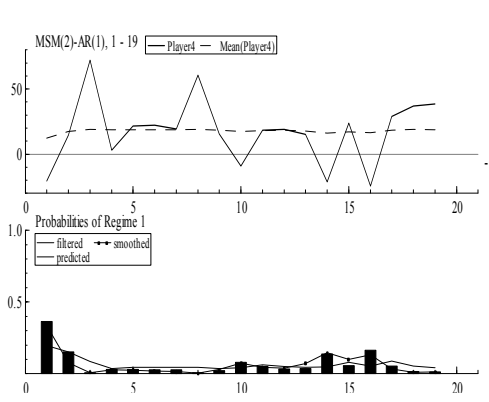

Player 7
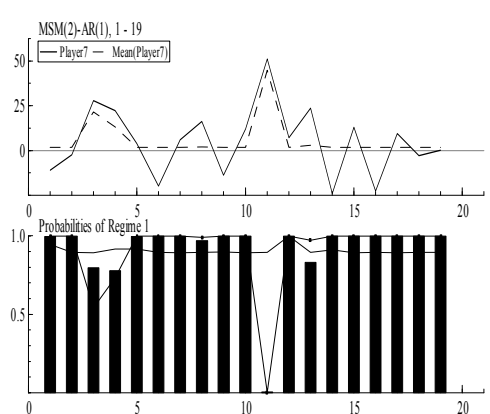

Player 10

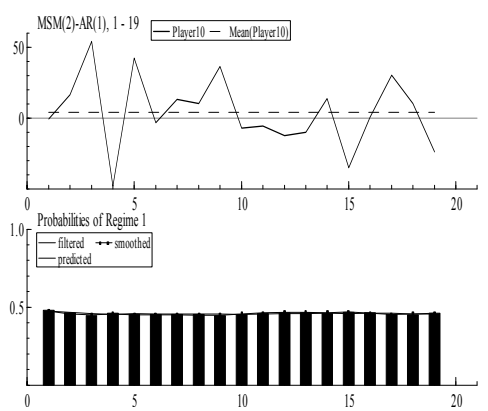

Player 13

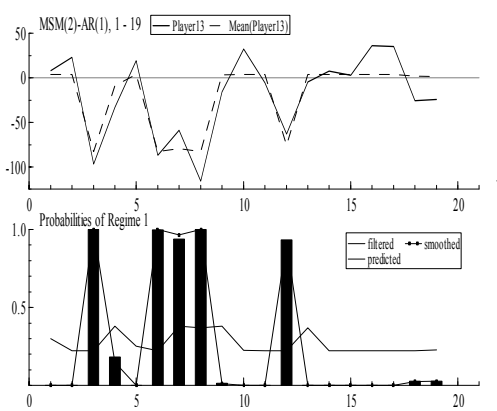

Player 2

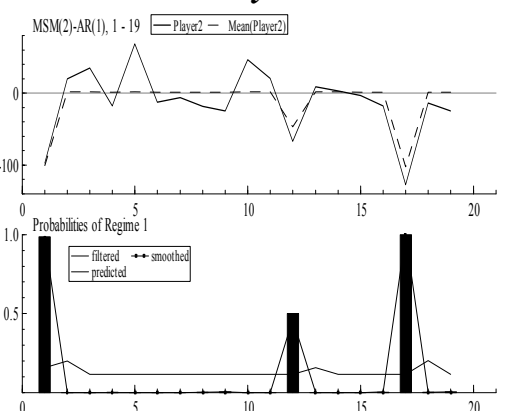

Player 5

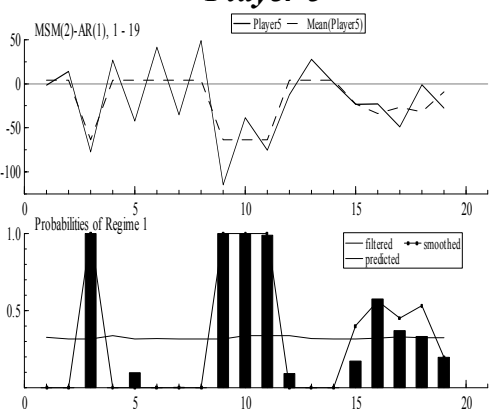

Player 8
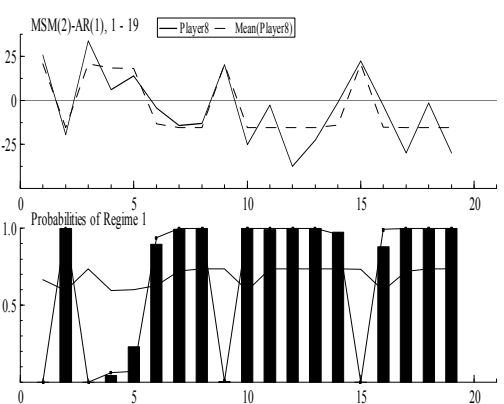

Player 11

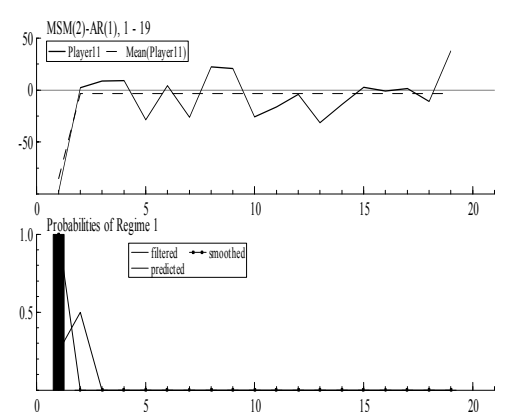

Player 14

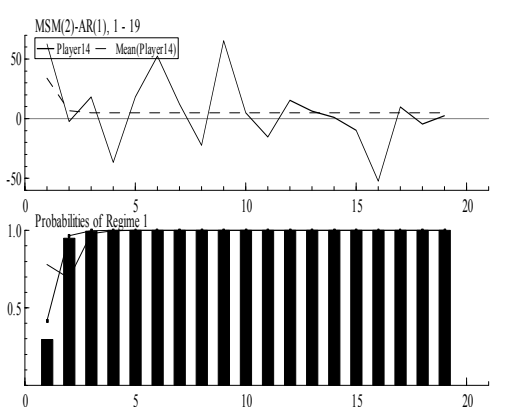

Player 3

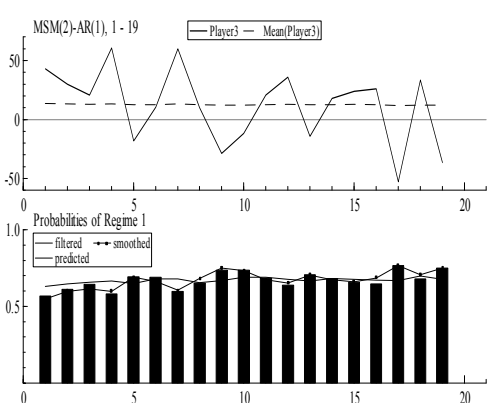

Player 6

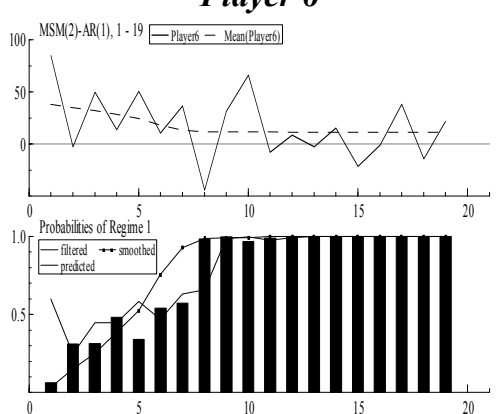

Player 9

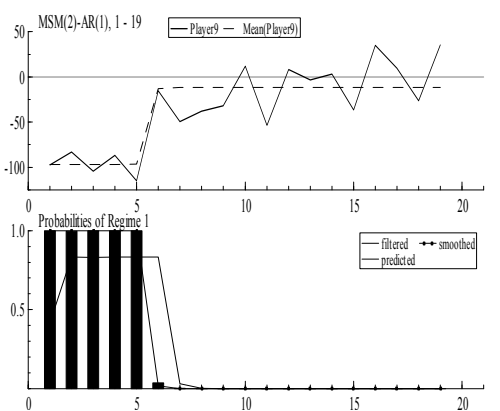

Player 12

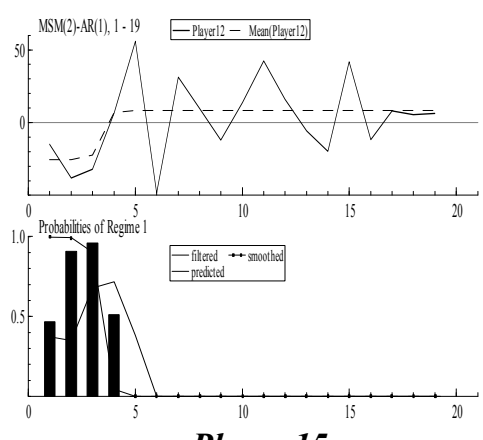

Player 15

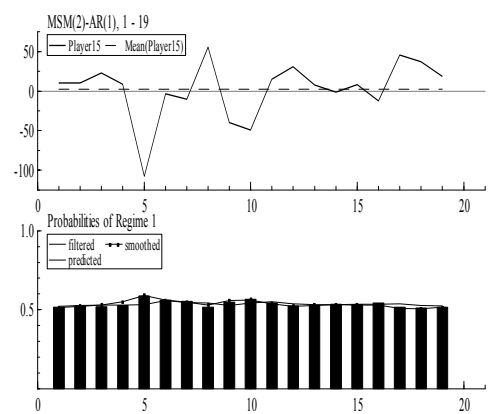


Figure 9: Smoothed Probabilities of Regime 1 (Cournot HP)

Player 1
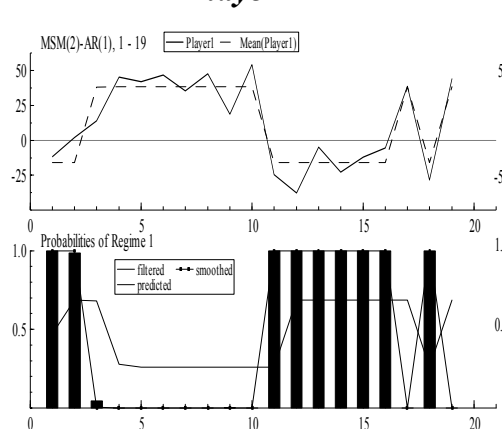

Player 4

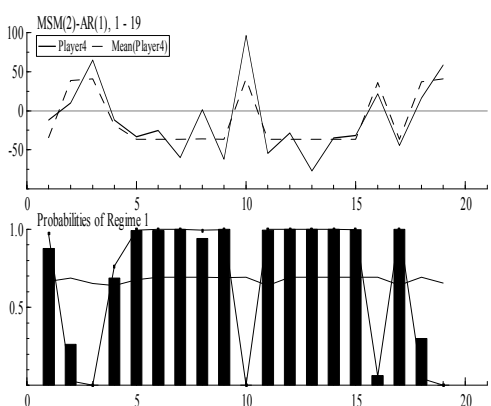

Player 7

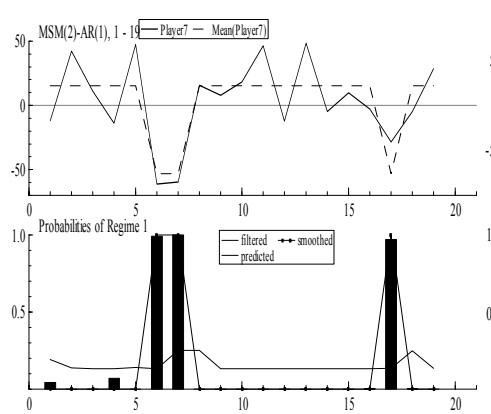

Player 10
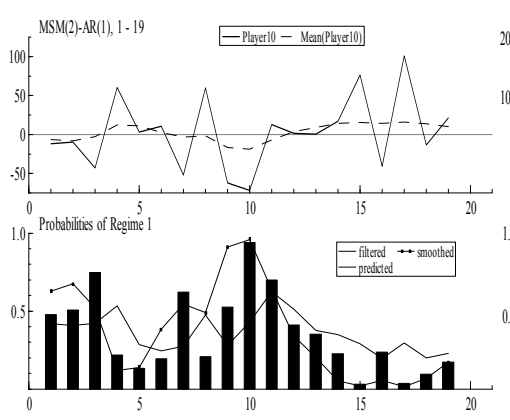

Player 15
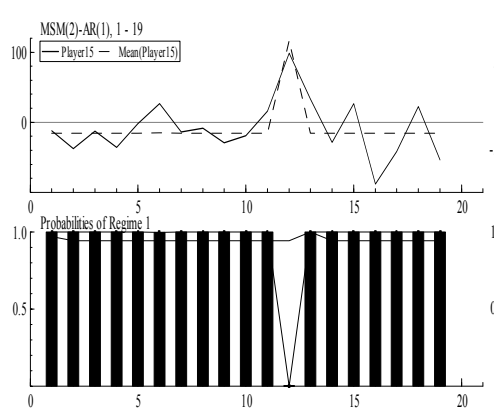

Player 2

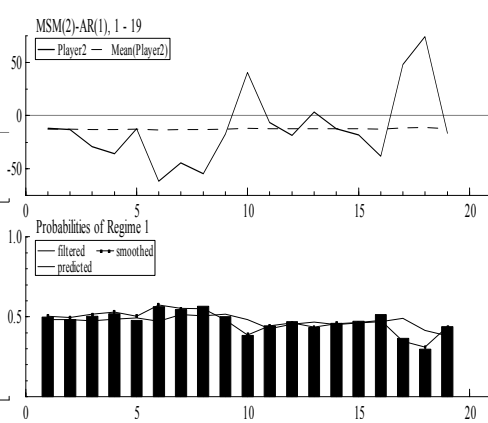

Player 5

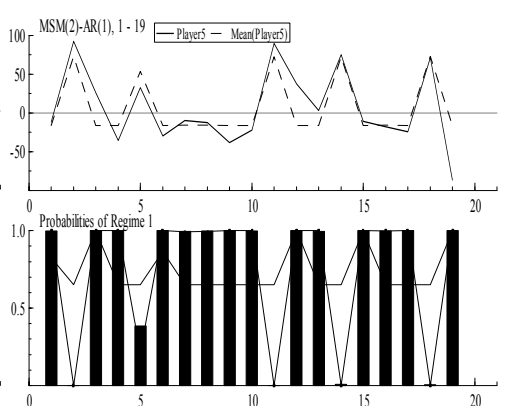

Player 8

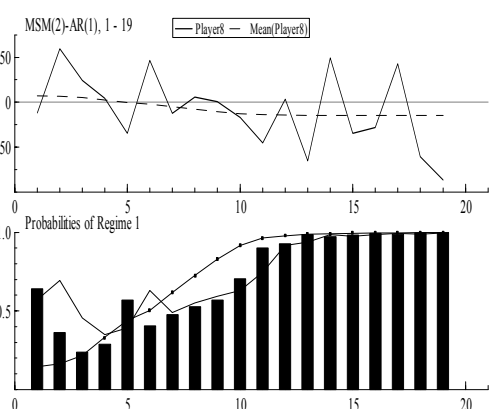

Player 11

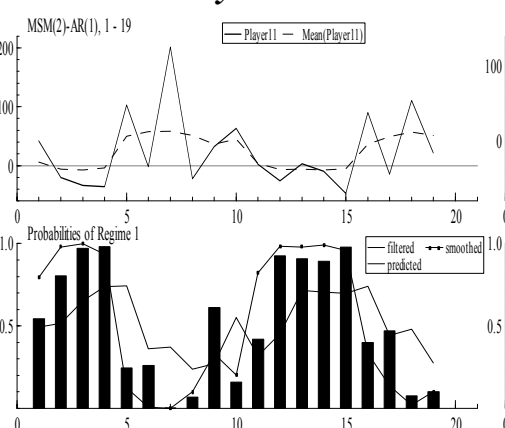

Player 16

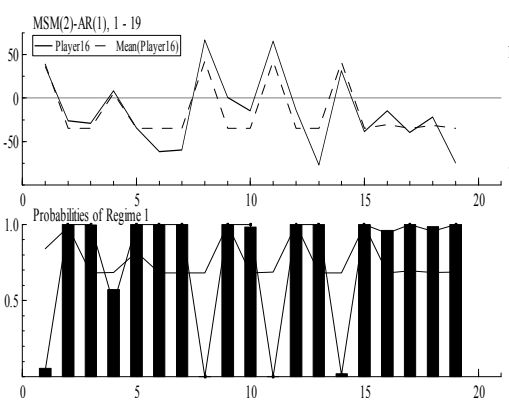

Player 3

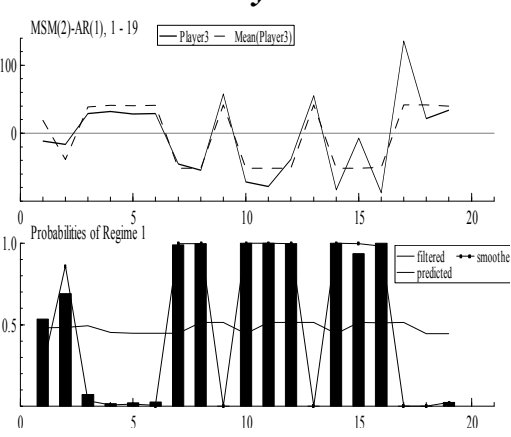

Player 6

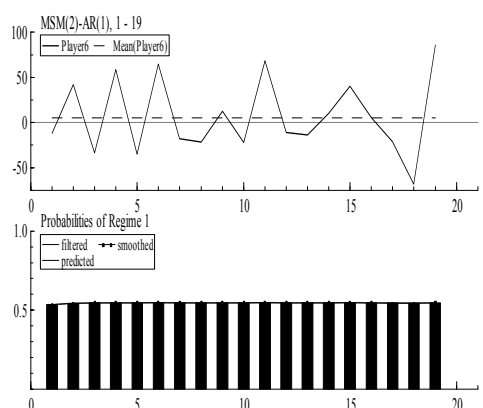

Player 9

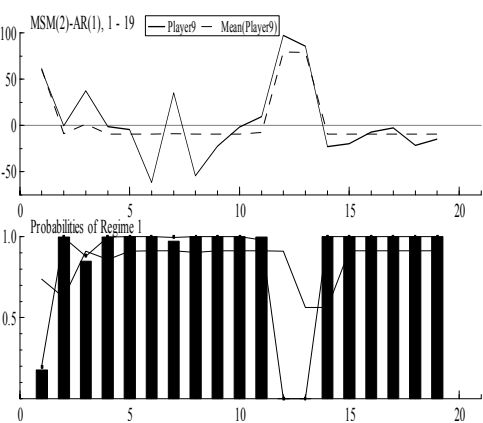

Player 12
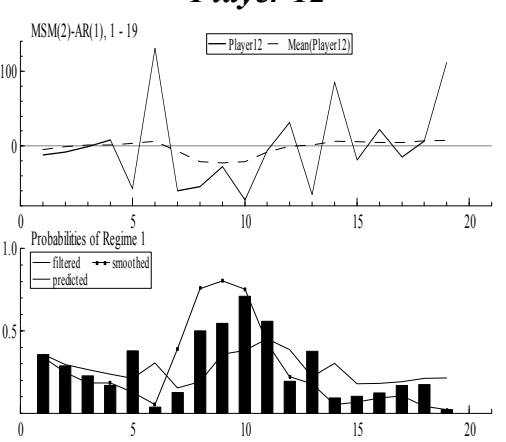

Player 18
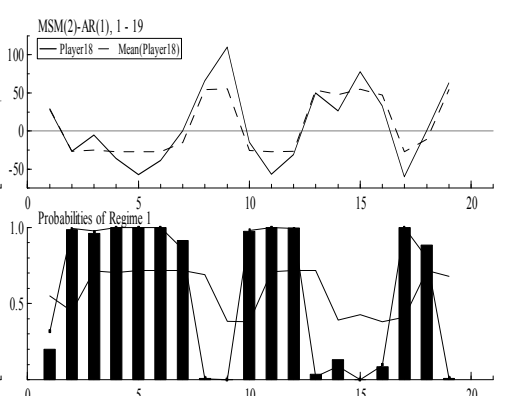
FIGURE 1: AVERAGE QUANTITIES (ED 1)

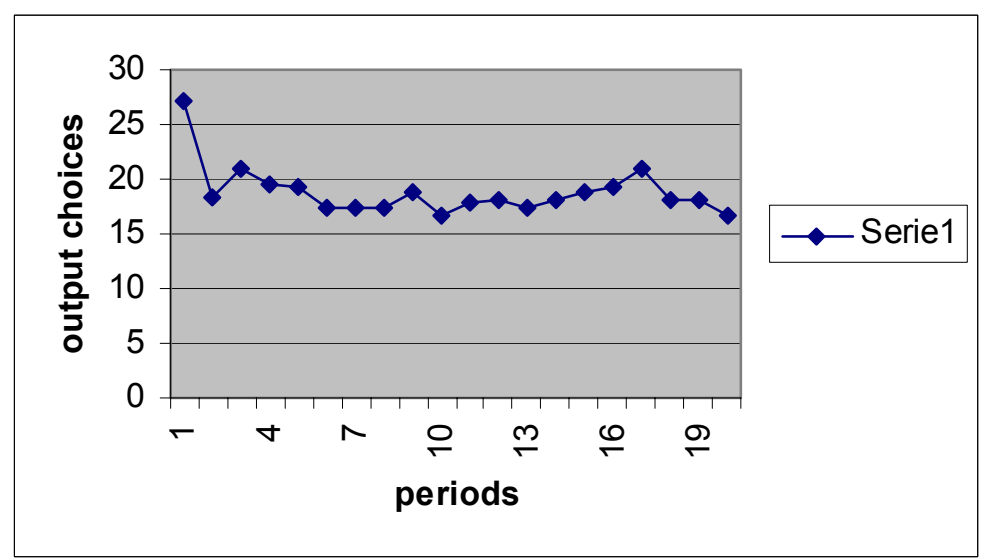

FIG. 1A: COURNOT MARKET (H.P.)

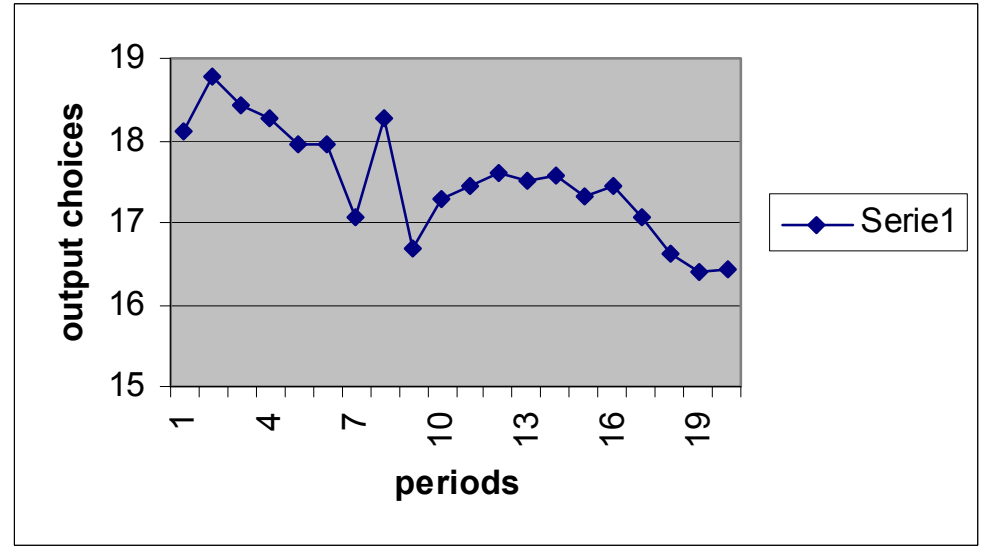

FIG. 1B: COURNOT MARKET (D.P.)

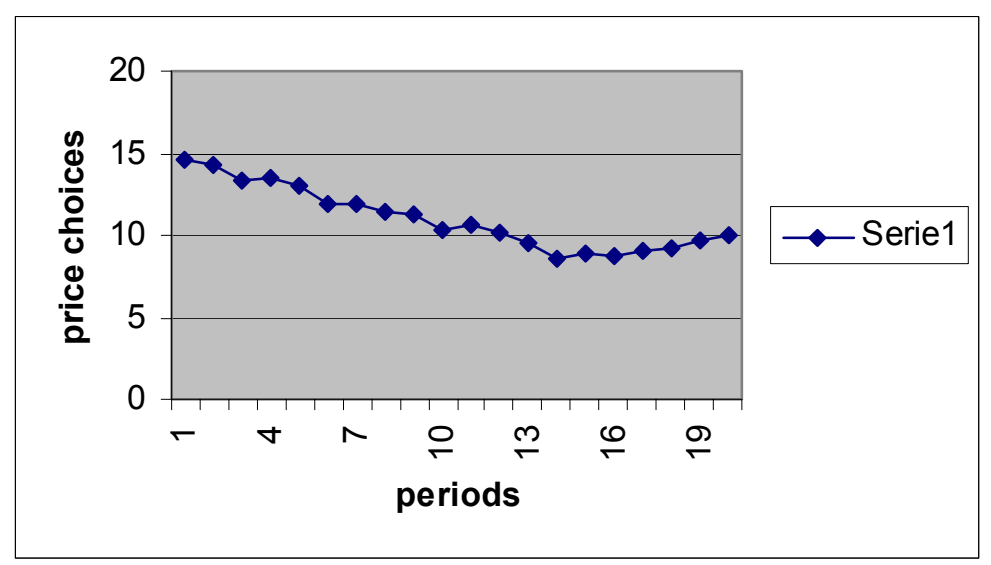

FIG. 1C: BERTRAND MARKET (D.P.) 
FIGURE 2: FREQUENCY OF STRATEGIES (ED1)

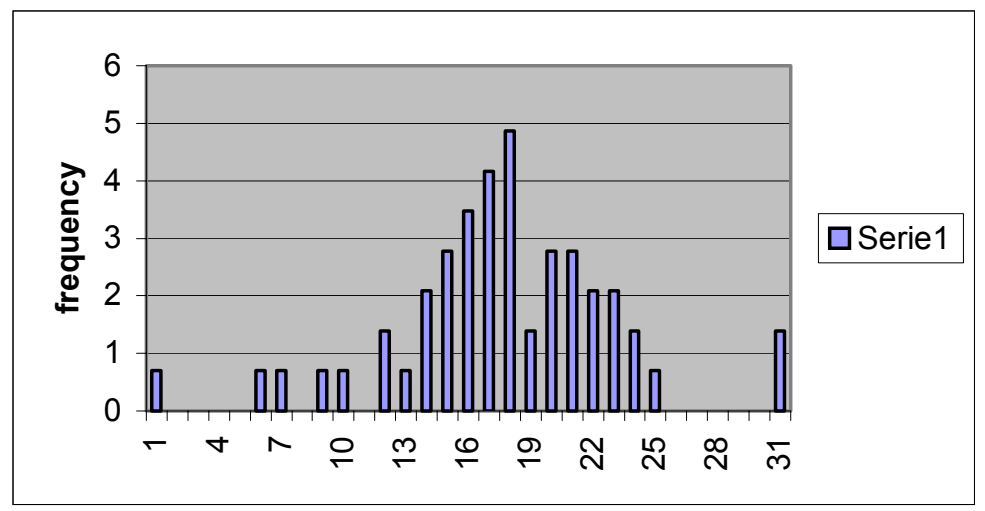

FIG. 1A: COURNOT MARKET (H.P.)

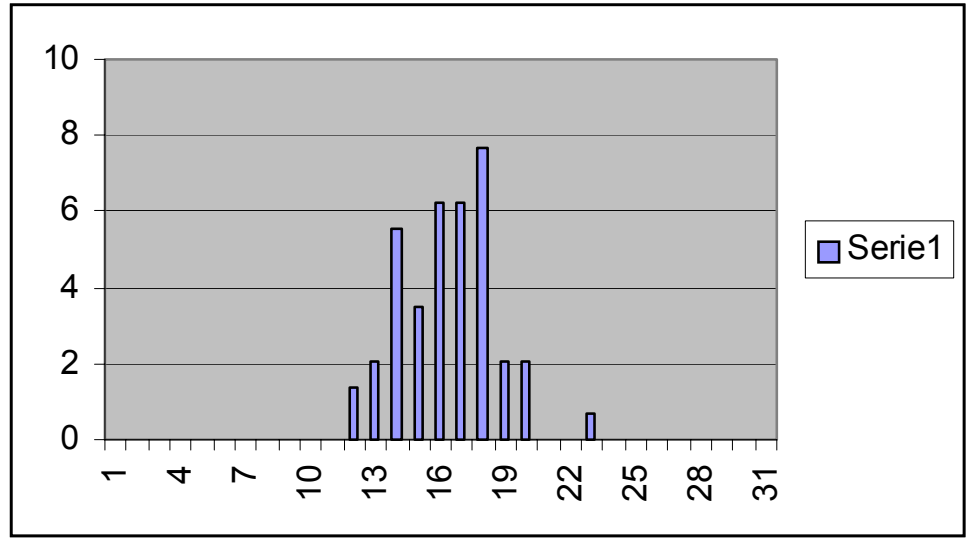

FIG. 2B: COURNOT MARKET (D.P.)

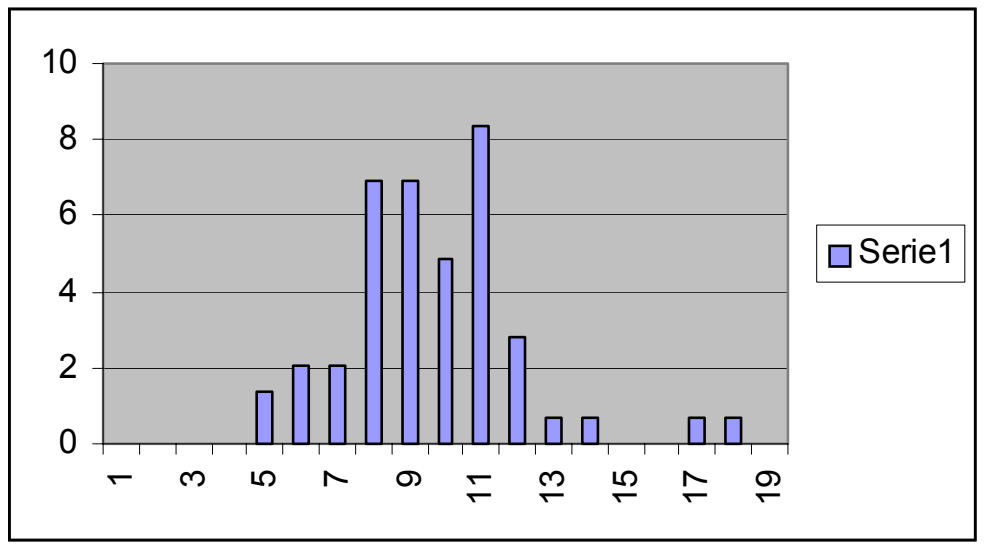

FIG. 2C: BERTRAND MARKET (D.P.) 
FIGURE 3: AVERAGE QUANTITIES (ED 2)

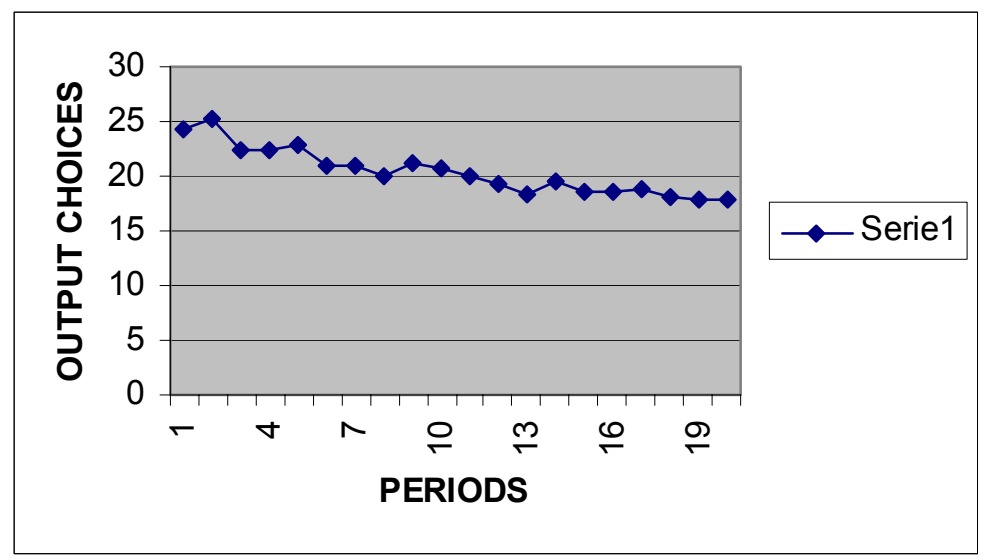

FIG. 3A: COURNOT MARKET (H.P.)

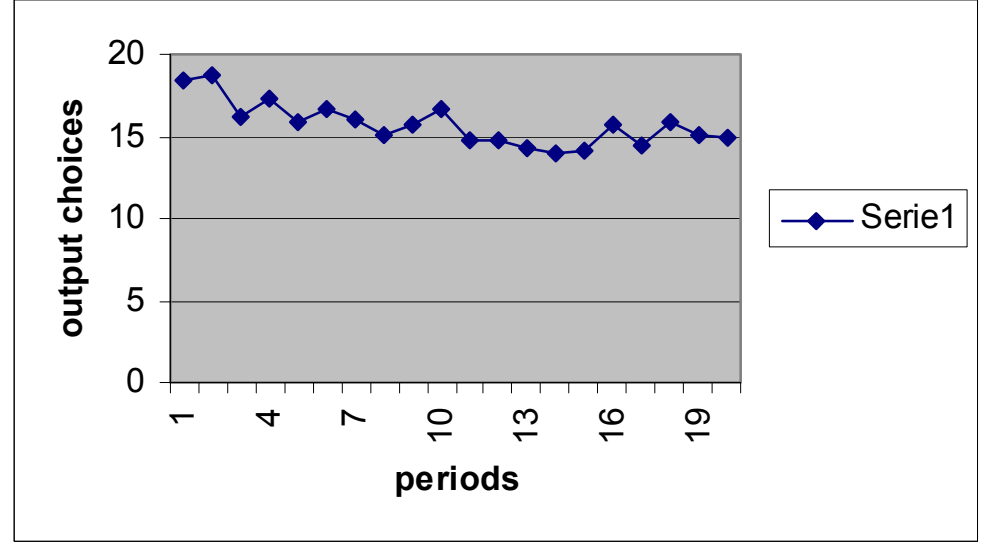

FIG. 3B: COURNOT MARKET (D.P.)

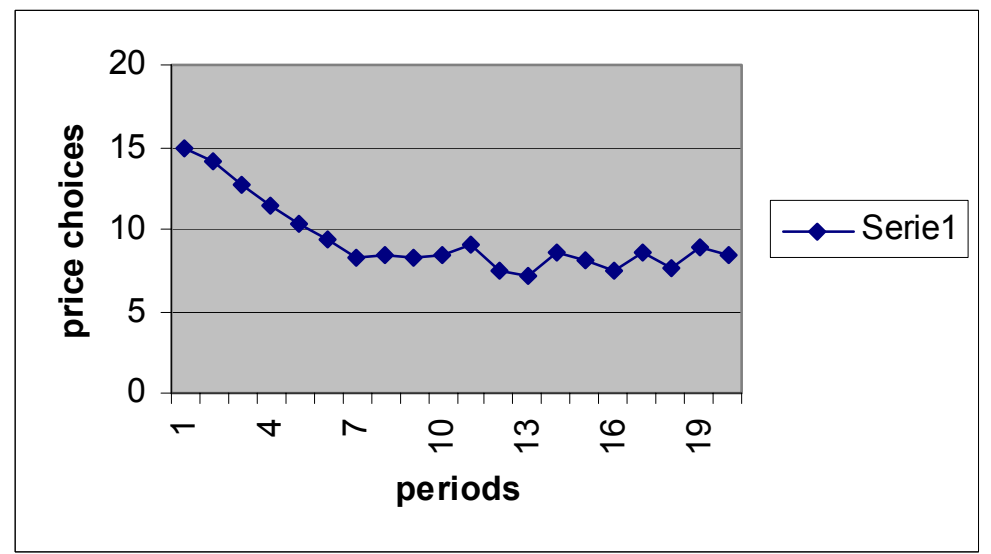

FIG. 3C: BERTRAND MARKET (D.P.) 
FIGURE 4: FREQUENCY OF STRATEGIES (ED 2)

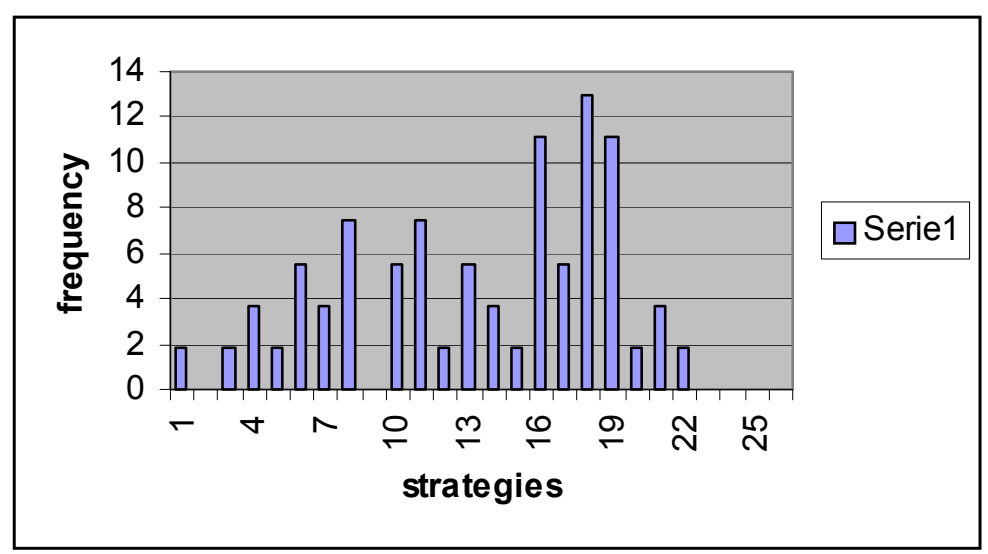

FIG. 4A: COURNOT MARKET (H.P.)

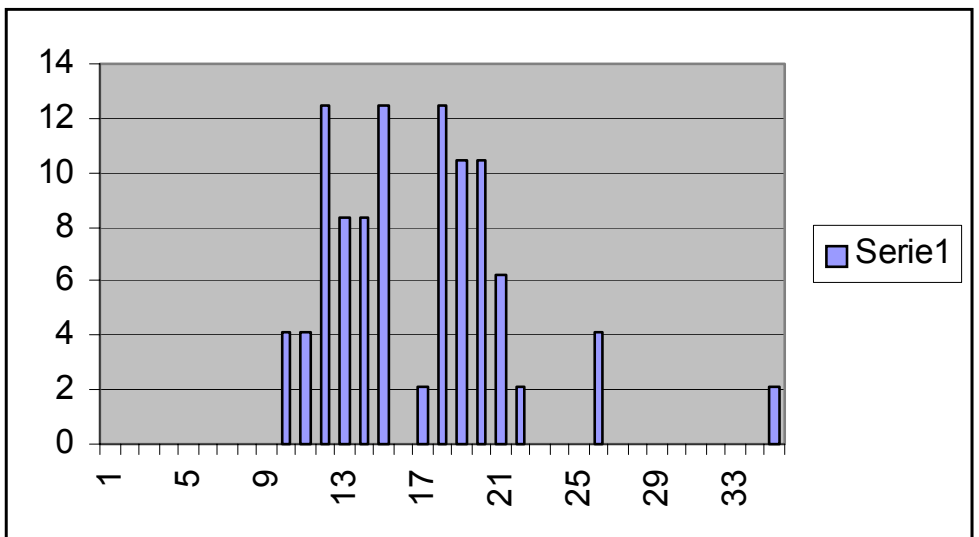

FIG. 4B: COURNOT MARKET (D.P.)

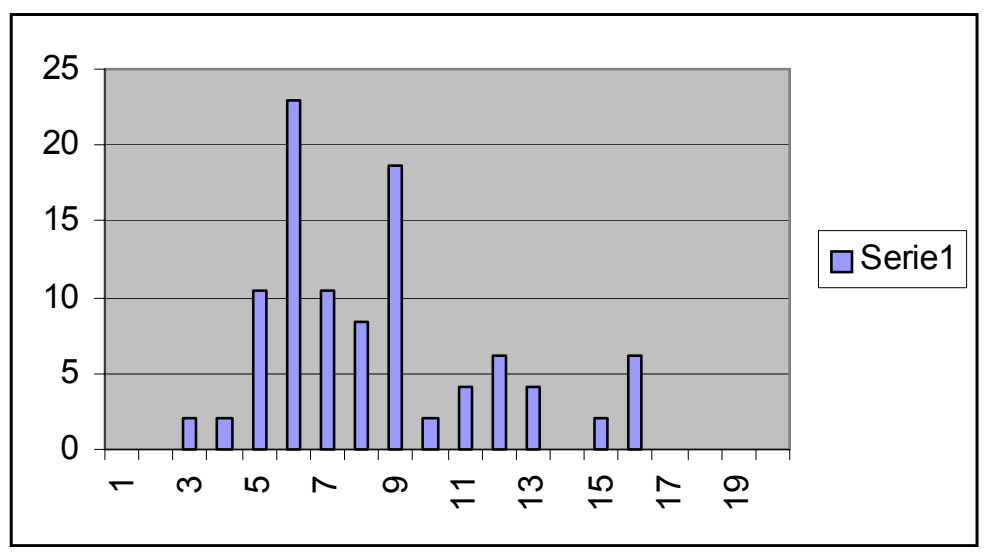

FIG. 3C: BERTRAND MARKET (D.P.) 
FIGURE 5: AVERAGE QUANTITIES (ED 3)

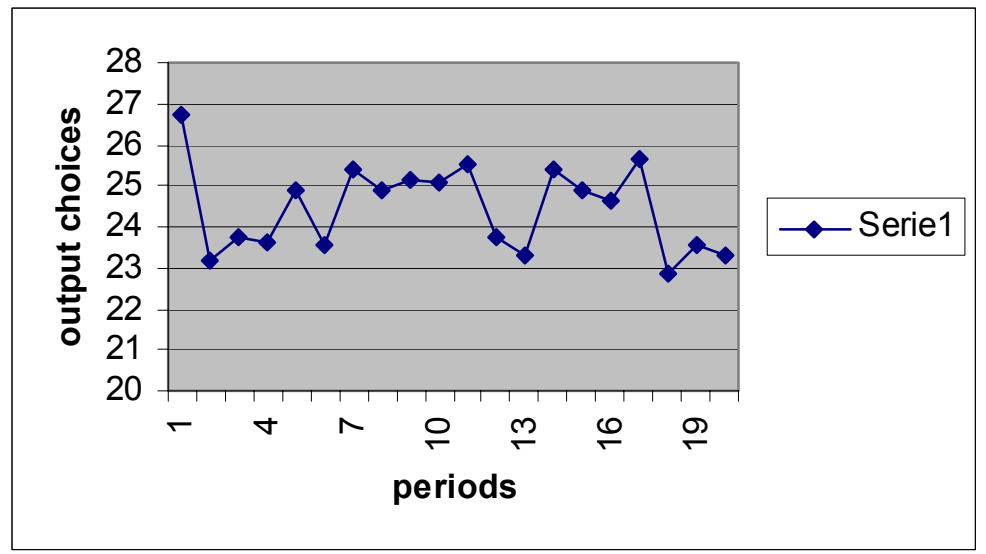

FIG. 5A: COURNOT MARKET (H.P.)

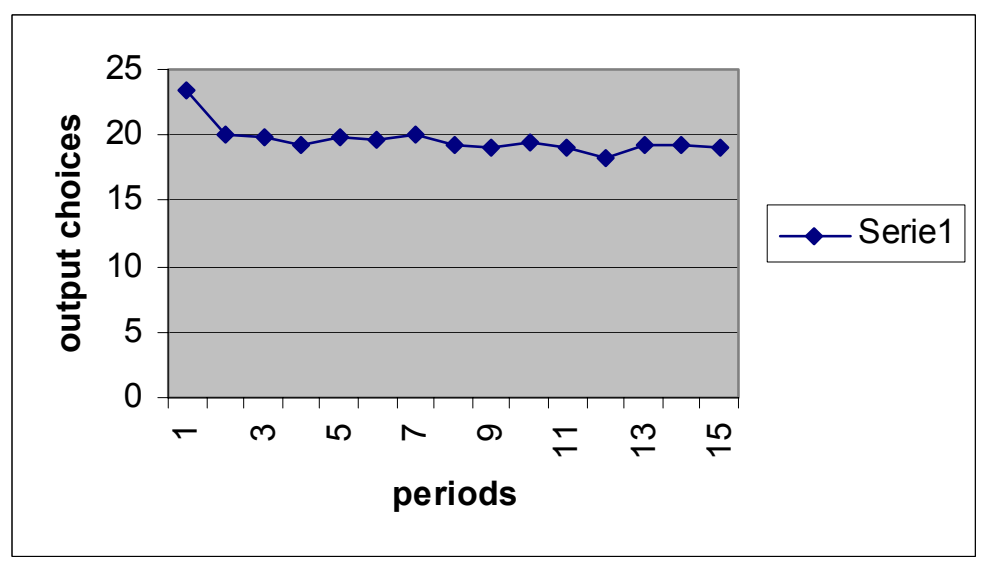

FIG. 5B: COURNOT MARKET (D.P.)

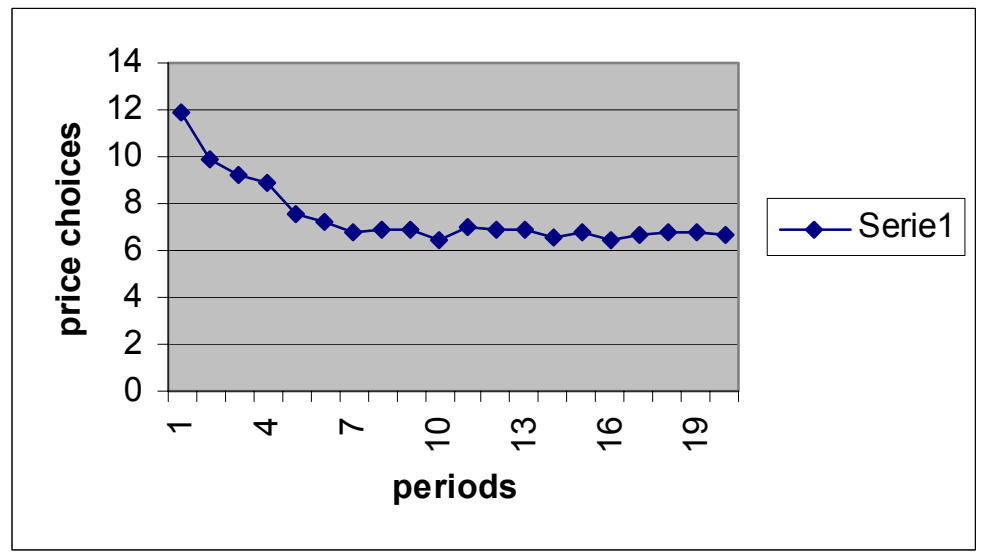

FIG. 5C: BERTRAND MARKET (D.P.) 
FIGURE 6: FREQUENCIES OF STRATEGIES (ED 3)

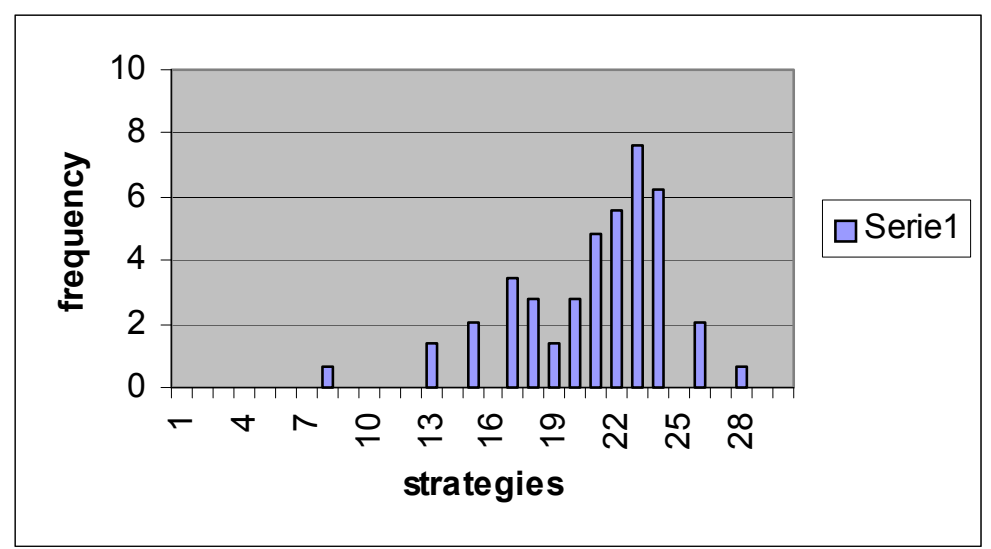

FIG. 6A: COURNOT MARKET (H.P.)

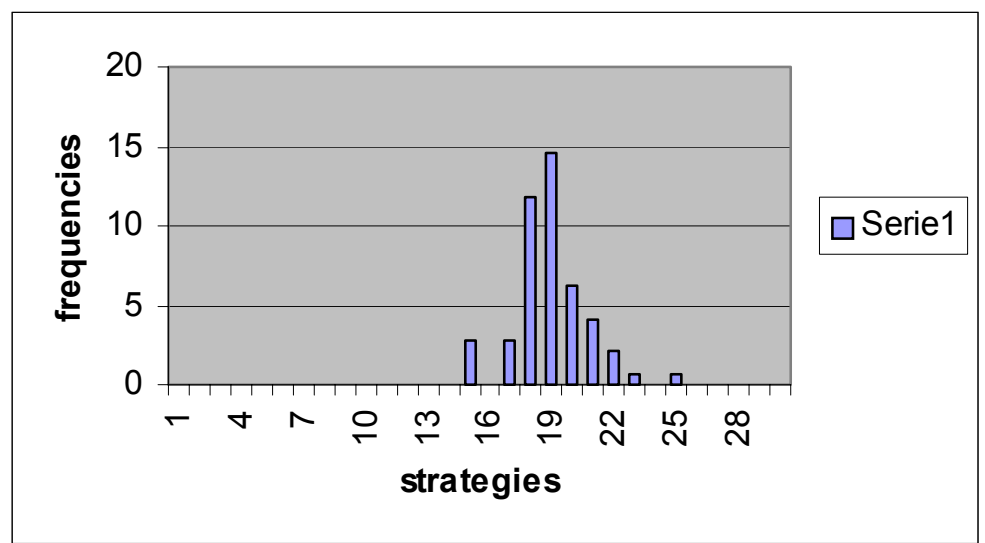

FIG. 6B: COURNOT MARKET (D.P.)

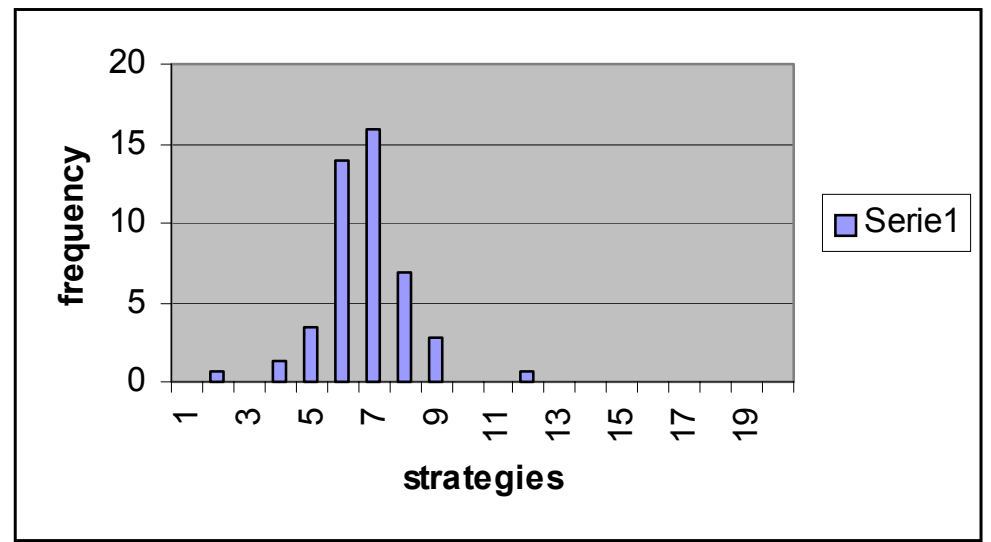

FIG. 6C: BERTRAND MARKET (D.P.) 